\title{
Demonstrated large-scale production of marine microalgae for fuels and feed
}

\author{
Mark E. Huntley ${ }^{12 c *}$ \\ Zackary I. Johnson ${ }^{3}$ \\ Susan L. Brown ${ }^{4}$ \\ Deborah L. Sills ${ }^{56}$ \\ Léda Gerber ${ }^{\mathrm{e}}$ \\ Ian Archibald ${ }^{8}$ \\ Stephen C. Machesky ${ }^{9}$ \\ Joe Granados ${ }^{\mathrm{j}}$ \\ Colin Beal ${ }^{\mathrm{k}}$ \\ Charles H. Greene ${ }^{\mathrm{e}}$
}

${ }^{1}$ Cornell University, Department of Biological and Environmental Engineering, Riley-Robb, 111 Wing Drive, Ithaca, NY 14853, United States

${ }_{3}^{2}$ Cellana LLC, 73-4460 Queen Ka'ahumanu Highway, Kailua-Kona, HI 96740, United States

${ }^{3}$ Duke University, Marine Laboratory (Nicholas School of the Environment) and Department of Biology, 135 Duke Marine Lab Road, Beaufort, NC 28516, United States

4 University of Hawaii at Manoa, Department of Oceanography, MSB 205, 1000 Pope Road, Honolulu, HI 96822, United States

${ }^{5}$ Cornell University, Department of Earth and Atmospheric Sciences, 4120 Snee Hall, Ithaca, NY 14853, United States

${ }^{6}$ Bucknell University, Department of Civil and Environmental Engineering, 215 Dana Engineering, Lewisburg, PA 17837, United States

${ }^{7}$ Cornell University, Department of Chemical and Biomolecular Engineering, 120 Olin Hall, Ithaca, NY 14853, United States

${ }^{8}$ Cinglas Ltd, Chester, United Kingdom

' KCPM Inc., dba Kokua Contracting and Project Management, 77-6441 Kuakini Highway, Kailua-Kona, HI 96740, United States

I Institute for Integrated Renewables, 73-4617 Kaloko Halia Place, Kailua-Kona, HI 96740, United States

${ }^{k}$ B\&D Engineering and Consulting LLC, 7419 State Hwy 789, Lander, WY 82520, United States

* Corresponding author. Tel: +1 8086404239

E-mail addresses: meh333@cornell.edu (M. Huntley), zij@duke.edu (Z. Johnson), sbrown@soest.hawaii.edu (S. Brown), deborah.sills@bucknell.edu (D. Sills), Ing28@cornell.edu (L. Gerber), ia@algae-architects.com (I. Archibald), smachesky@kcpm.net (S. Machesky), mrgranados@gmail.com (J.Granados), colinmbeal@gmail.com (C. Beal), chg2@cornell.edu (C. Greene) 


\begin{abstract}
We present the results from sustained tonne-quantity production of two novel strains of marine microalgae, the diatom Staurosira and the chlorophyte Desmodesmus, cultivated in a hybrid system of $25-\mathrm{m}^{3}$ photobioreactors and $400-\mathrm{m}^{2}$ open ponds at a large-scale demonstration facility, and then apply those results to evaluate the performance of a 100-ha Base Case commercial facility assuming it were built today. Nitrogen fertilization of 2-d batch cultures in open ponds led to the greatest yields - from both species - of $\sim 75 \mathrm{MT} \mathrm{ha}^{-1} \mathrm{yr}^{-1}$ biomass, and $\sim 30 \mathrm{MT} \mathrm{ha}^{-1} \mathrm{yr}^{-1}$ lipid, which are unprecedented in large scale open pond systems. The process described here uses only seawater, discharges no nitrogen or phosphorus in any form, and consumes $\mathrm{CO}_{2}$ at $78 \%$ efficiency. We estimate the capital cost of a 111-ha Base Case facility at \$67 million in Hawaii, where actual production was performed, and \$59 million on the Gulf Coast of Texas. We find that large-diameter, large-volume PBRs are an economical means to maintain a continuous supply of consistent inoculum for very short-period batch cultures in open ponds, and thus avoid biological system crashes that otherwise arise in longer-term pond cultures. We recommend certain improvements in cultivation methods that could realistically lead to yields of $100 \mathrm{MT} \mathrm{ha}^{-1} \mathrm{yr}^{-1}$ biomass and $>50,000 \mathrm{~L} \mathrm{ha}^{-1} \mathrm{yr}^{-1}$ algal oil. Comprehensive techno-economics and life cycle assessment of 20 endto-end production lineups, based on the cultivation results in this paper, are presented in a companion paper by Beal et al [1].
\end{abstract}

KEYWORDS: Algae; Biofuel; Animal feed; Cultivation; Nitrogen; Economics 


\section{Introduction}

The potential for fuel and feed production from microalgae has been recognized for decades.

However, despite significant progress, reliable and cost-effective production of lipid- and protein-rich algal biomass have not been demonstrated at scales $>10 \mathrm{~m}^{2}$. Productivity and cost remain the two fundamental barriers to commercialization.

Prior evaluations of the economic and environmental viability of algal biofuels rely on one of the following methods to estimate biomass and lipid productivity: (1) assumed values, (2) modeled values based on climatology, or (3) measured values based on long-term outdoor production in a scalable system [1]. Studies that use assumed values for biomass and lipid productivity project yields ranging from 50 to $>100 \mathrm{MT} \mathrm{ha}^{-1} \mathrm{yr}^{-1}$ biomass and from 5 to $>50 \mathrm{MT} \mathrm{ha}^{-1} \mathrm{yr}^{-1}$ lipid, whether in open ponds [2-17] or PBRs $[7,14]$, clearly revealing the wide uncertainties of this approach. Modeling studies may incorporate sitespecific climatology, but they predict a similar wide range of biomass and lipid yields from both ponds and PBRs [18-23]. To date the few reports of directly measured yields from open ponds at a scale $>10 \mathrm{~m}^{2}$ are an order of magnitude lower than assumed or modeled yields [10, 12, 24-26]. By comparison, small diameter PBRs can actually produce sustained yields at assumed or modeled rates, but their high cost [27, 28] has led to the conclusion that PBRs are too costly to be employed for biofuel production $[4,6,22]$.

Furthermore, several recent economic analyses or life cycle assessments presume that lipid yields can be significantly increased by reducing available nitrogen, but this has not been well demonstrated.

The prime goals of this study are to (1) report results from dozens of demonstration-scale experiments that evaluate the critical cultivation conditions affecting biomass and lipid yield and then (2) extend those results to inform techno-economic and life cycle assessments of microalgae cultivation and harvesting. We analyze the results of realized, sustained production of two strains of marine microalgae, the diatom Staurosira sp. and the chlorophyte Desmodesmus sp., cultivated in a hybrid PBR-pond system [29] at the 0.5-ha demonstration scale Kona Demonstration Facility (KDF) in Kona, Hawaii. These strains were selected from a comprehensive screening study of $>500$ novel isolates, and the tons of biomass 
harvested from both species were processed for fuel and feed trials. Further, we apply the KDF results to design a 100-hectare "Base Case" facility were it to be built today.

In addition to the direct quantification of the yields of biomass and lipid at large scale, this study tests at a commercially relevant scale some of the prevailing notions in the field of algal biofuel production, namely that (1) less nitrogen $(\mathrm{N})$ yields more lipid $[9,15,30],(2)$ that realized lipid yields from conventional open ponds are too low for economical production $[6,31,32]$, and (3) that the cost of PBRs is too high $[7,20,33]$. First, we quantify the effect of $\mathrm{N}$ fertilization on productivity, lipid yield, and biomass composition in long-term, large-scale demonstration trials. Second, we compare lipid yields

34 from open ponds in a hybrid system to those from conventional open ponds. Third, we evaluate the 35 overall cost of the hybrid cultivation system, including the actual large-volume PBRs used in this study, 36 and compare those to the cost of a conventional open pond system occupying the same area.

The functional unit of this study is 1 hectare of cultivation area, which facilitates comparison with more conventional biomass production systems based on terrestrial plants. The cultivation and harvesting process analyzed here delivers the biomass of marine microalgae as a viscous slurry, $20 \%$ total suspended solids (TSS), amenable to further separation into 2 co-products: (1) a "biocrude" oil fraction, and (2) a

41 residual protein-rich fraction, each suitable as a feedstock for refined fuels and animal feeds, respectively.

42 The biomass production process chain at KDF consists of a hybrid cultivation system of PBRs and open

43 raceway ponds, a harvesting system of natural settling and centrifugation, followed by drying and hexane

44 extraction. The Base Case cultivation process is based directly on yields from the sustained KDF

45 production experiments, while the processing chain includes natural settling and a filter press, followed

46 by Valicor biomass conversion technology [12], which latter processes were demonstrated in smaller

47 scale trials. Comprehensive techno-economics and LCA for the entire production process, incorporating

48 the results of this paper, are provided by Beal et al. [1]. This paper addresses the techno-economic

49 feasibility of the cultivation process in particular, based on measurements of long-term, sustained

50 production at demonstration scale, thus providing a firm foundation from which to advance the 
51 understanding of large-scale production and narrowing the gap between validated results and optimistic

52 models and assumptions.

\section{Materials and Methods}

\subsection{Strain selection}

The purpose of strain selection is to rapidly identify algae that are highly productive under largescale production conditions. Species characteristics of primary value for cultivation and harvesting are rapid growth, and high yields of both lipid and protein in batch culture using a low-cost source of nitrogen, which also has low environmental impact in its manufacture. The ideal strain is both temperature- and salt-tolerant; upon nutrient exhaustion it is negatively buoyant, enhancing gravitational separations in the harvesting process. The ash content is low, as it has little value. sp. and the Chlorophyte Desmodesmus sp., by screening hundreds, as follows. We selected strains from the local marine environment throughout the Hawaiian Islands. In less than a year, $>500$ novel strains were isolated from local waters and pre-screened in 30-ml test tube cultures for temperature tolerance $\left(20^{\circ}, 25^{\circ}\right.$, and $\left.30^{\circ} \mathrm{C}\right)$ and high growth rate, estimated from daily measurements of in vivo fluorescence

66

\section{[34].}

The High-Throughput Screening (HTS) program evaluated 171 pre-screened strains in duplicate trials at three separate laboratories (JJ Cullen, Dalhousie University; DR Redalje, The University of Southern Mississippi; Z Johnson, Duke University). In the first stage of HTS, strains were first acclimated for $>10$ generations to $25^{\circ}, 30^{\circ}$, and $35^{\circ} \mathrm{C}$, then grown in triplicate under both nutrient-replete and nutrientstarved conditions in 50-ml cultures for two weeks, and each measured daily as shown in Table 1; a fluorescence-based sinking index was measured at the end of each experiment. Strain performance was ranked using a combination of 17 directly measured and derived variables to identify strains for further study. The second stage of HTS investigated the impact of nitrogen source, offered as either $\mathrm{NH}_{4}$ or $\mathrm{NO}_{3}$, and lipid biochemistry was characterized in more detail. The top 24 strains were grown at $30^{\circ} \mathrm{C}$ under 
76 Table 1 Measured variables at each screening level: Pre-Screening (PS), High-Throughput (HTS), Mid-

77 Scale (MSS), and Large-Scale Production (LSP), showing continuous measurements $(\odot)$, the number of

78 daily measurements in all cultures (1),(2),(3) and those made only in ponds $(\mathbf{0}, \mathbf{2}, \mathbf{3})$, for the total number

79 of strains at each screening level. Multiple daily measurements in MSS and LSP included morning (06.00

80 to $08.00 \mathrm{LT})$ and evening $(16.00$ to $18.00 \mathrm{LT})$ sample times. M.O. = microscope observations; $\mathrm{OD}_{440}=$

81 optical density at $440 \mathrm{~nm} ; \mathrm{POC}=$ particulate organic carbon; $\mathrm{PON}=$ particulate organic nitrogen.

\begin{tabular}{|c|c|c|c|c|c|}
\hline \multirow[b]{2}{*}{ Measurement } & \multicolumn{4}{|c|}{ Screening Level } & \multirow[b]{2}{*}{ References } \\
\hline & PS & HTS & MSS & LSP & \\
\hline PAR & & (1) & $\odot$ & $\odot$ & {$[35]$} \\
\hline Temperature & (1) & (1) & $\odot$ & $\odot$ & {$[36]$} \\
\hline $\mathrm{pH}$ & & & $\odot$ & $\odot$ & {$[36]$} \\
\hline M.O. & (1) & (1) & (1) & (1) & {$[35]$} \\
\hline $\mathrm{NH}_{4}, \mathrm{NO}_{2}, \mathrm{NO}_{3}$ & & (1) & (3) & (2) & {$[37]$} \\
\hline $\mathrm{PO}_{4}, \mathrm{SiO}_{4}$ & & (1) & (3) & (2) & {$[37]$} \\
\hline $\mathrm{OD}_{440}$ & & (1) & (3) & (2) & {$[34]$} \\
\hline in vivo fluorescence & (1) & (1) & (3) & (2) & {$[35]$} \\
\hline $\mathrm{F}_{\mathrm{v}} / \mathrm{F}_{\mathrm{m}}$ & (1) & (1) & (3) & (2) & {$[35]$} \\
\hline Dry weight & & (1) & (3) & 2 & {$[38]$} \\
\hline Ash-free dry weight & & (1) & (3) & 2 & {$[38]$} \\
\hline Chlorophyll $a$ & & (1) & (3) & 2 & {$[35]$} \\
\hline POC, PON & & (1) & (3) & 2 & {$[35]$} \\
\hline Nile Red & & (1) & (3) & 2 & {$[35]$} \\
\hline Total lipid & & (1) & 3 & 2 & [39] \\
\hline Triacylglycerols & & (1) & 3 & 2 & {$[40]$} \\
\hline Sinking rate & & (1) & (1) & (1) & {$[36]$} \\
\hline Number of strains & $>500$ & 171 & 16 & 2 & \\
\hline
\end{tabular}

82

83 nutrient-replete and nutrient-starved conditions using both $\mathrm{NH}_{4}$ and $\mathrm{NO}_{3}$. The same variables were

84 measured as in first stage HTS, plus total lipids, total triacylglycerols, and other lipid classes.

85 The Mid-Scale Screening (MSS) program evaluated the top 16 strains from HTS for productivity, 86 lipid composition, and harvestability. Cultures were grown under outdoor conditions at KDF using a 
system of twelve 200-L, pre-sterilized scale-up reactors (see Section 1.2: KDF system description) to simulate PBRs, and twelve 200-L paddlewheel-driven "mini-ponds" to simulate ponds; the first several trials used 50-L plexiglass cylinders to simulate the operation of both PBRs and ponds until mini-ponds were fully operational. All strains were grown in $\mathrm{f} / 2$ medium [41], with $\mathrm{NO}_{3}$ as the nitrogen source and $\mathrm{Si}(\mathrm{OH})_{4}$ included only for diatoms. During each 15-d MSS trial, four strains were screened in triplicate reactors, operated to simulate both PBRs and ponds. Six MSS trials were conducted, all using the bestperforming of the first four strains, Staurosira sp., as an internal control, for which representative results (Fig 1) illustrate the trial process. For each trial, there were three modes of culture management, representing primary operations at large scale. The "Full Growth Curve" is the scale-up process used in the Base Case, wherein cultures are grown with sufficient dissolved inorganic nitrogen (DIN) to inoculate PBRs. The "PBR" mode simulates the repeated daily dilution of commercial-scale PBRs for 5 days; cultures were grown semi-continuously, harvested at the end of each day when nutrients were depleted, then replenished with nutrients. The final "Pond" mode simulates the operation of final batch cultures, inoculated with exponentially-growing PBR culture and grown beyond DIN depletion for up to 5 days.

103 Sinking rates were measured at $12.00 \mathrm{~h}$ each day of the pond run, and at $16.00 \mathrm{~h}$ on day 4 , the final

104 "harvest day," using an 8-ml test tube method, which measures settling over a distance of $7.4 \mathrm{~cm}$ in $1 \mathrm{~h}$ 105 or, at harvest time, using a 1-L graduated cylinder method, which measures settling at three depths $(0,15$, $10630 \mathrm{~cm})$ over $3 \mathrm{~h}$.

\subsection{KDF system description} by the co-authors of this paper Huntley, Machesky, and Archibald, is located on a coastal site, $5 \mathrm{~m}$ above

110 sea level, at the Hawaii Ocean Science and Technology Park on the island of Hawaii. The hybrid

111 cultivation and harvesting system consists of 0.5 hectare of PBRs and ponds, facilities for additional

112 dewatering by centrifugation and propane-fueled drying using a ring dryer, and is scaled to cultivate and 
113 process $\sim 3$ tons dry weight biomass per month. Fresh seawater from a nearshore intake depth of $30 \mathrm{~m}$ is

114 supplied to both PBRs and ponds; the supply to PBRs is pretreated by two-stage filtration to $0.2 \mu \mathrm{m}$

115 nominal pore size, followed by UV treatment. Commercial sources supply a regular 1-month supply of

116 carbon dioxide, at $>99 \%$ purity, stored in liquid form on site, and distributed as a gas to PBRs and ponds;

117 fertilizers are supplied in solid form and pre-mixed on site to highly concentrated stock solutions, which

118 are then delivered as concentrate $(\sim 1000 \times)$ to ponds, or pre-diluted in the seawater supply to PBRs.

119 Dispensing of $\mathrm{CO}_{2}$ and nutrients from storage facilities to individual reactors is managed by a central

120 process-control system. Energy for all activities is provided by on-site generators.

121 The scale-up reactor is a 200-L vertical cylindrical bag, $0.38 \mathrm{~m}$ in diameter, made of clear

122 polyethylene, and structurally supported by a wire mesh cage. Customized bags were fabricated with

123 integrated fittings to our specifications, and shipped, pre-sterilized and ready for deployment. Bag

124 cultures are filled with fresh filtered and UV-sterilized medium, inoculated with a standard 20-L

125 laboratory culture, then, after a week or less can be harvested to inoculate PBRs. Bag cultures are

126 circulated by turbulent convection generated by continuous low-pressure air supplied to a diffuser at the

127 base of the reactor. Light exposure is comparable to that in horizontal tubular PBRs, which are the same

128 diameter (Table 2). A process control system monitors and controls $\mathrm{pH}$ at $8.1 \pm 0.1$, supplying $\mathrm{CO}_{2}$ on

129 demand by injection into the air supply. Temperature is monitored but not controlled.

PBRs are of the horizontal tubular, serpentine, airlift-driven type [42], which we have developed

131 for commercial application over the past two decades [29, 43]. These comparatively large reactors -0.38

$132 \mathrm{~m}$ diameter and $25 \mathrm{~m}^{3}$ culture volume $c f[27,44,45]$ - provide, in our experience, a highly reliable, easily

133 maintained, and continuous supply of high quality, cost-efficient inoculum for pond inoculation (Table 2).

134 The PBR consists of two lengths of flexible polyethylene tubing, 10-15 mil thickness, each

135 connected at one end by a simple $180^{\circ}$ "U"-tube, and at the other by a $180^{\circ}$ "End Assembly" that

136 incorporates a 2.5-m vertical airlift located at the edge of a terrace of the same height. The End Assembly 
137 is made of roto-molded polyethylene to accommodate valves and other specified PBR fittings and, like all

138 other PBR components, is entirely recyclable. PBRs are deployed on a reflective geotextile surface

139 Table 2 Physical design parameters of recirculating PBRs, comparing Base Case design to Actual

140 demonstration system. Numbers in bold emphasize key design differences. Seawater input power of 79

$141 \mathrm{kWh} \mathrm{ha} \mathrm{d}^{-1}$ is for Hawaii, increasing to $352 \mathrm{kWh} \mathrm{ha}^{-1} \mathrm{~d}^{-1}$ in Texas.

\begin{tabular}{|c|c|c|c|}
\hline Design Parameter & Units & Actual & $\begin{array}{l}\text { Base } \\
\text { Case }\end{array}$ \\
\hline \multicolumn{4}{|l|}{ Unit dimensions } \\
\hline Tube diameter & $\mathrm{m}$ & 0.38 & 0.38 \\
\hline Tube length & $\mathrm{m}$ & 245 & 490 \\
\hline Riser height & $\mathrm{m}$ & 2.5 & 2.5 \\
\hline Land area & $\mathrm{m}^{2}$ & 186 & 372 \\
\hline Fluid fullness & & 0.90 & 0.90 \\
\hline Culture volume & $\mathrm{m}^{3}$ & 25 & $\mathbf{5 0}$ \\
\hline Hydraulic radius & $\mathrm{m}$ & 0.115 & 0.115 \\
\hline Fluid velocity & $\mathrm{m} \mathrm{s}^{-1}$ & 0.40 & 0.40 \\
\hline Cycle time & $\min$ & 10 & 20 \\
\hline Reynolds number - night, $\operatorname{Re}_{N}$ & & 41,700 & 41,700 \\
\hline Reynolds number - day, $\operatorname{Re}_{\mathrm{D}}$ & & 54,900 & 54,900 \\
\hline Hydraulic power & $\mathrm{W}$ & 62 & 77 \\
\hline Airlift efficiency & $\%$ & 25 & 25 \\
\hline Unit Recirculation power & $\mathrm{kWh} \mathrm{d}^{-1}$ & 5.96 & 7.42 \\
\hline Dilution rate & $\% \mathrm{~d}^{-1}$ & 50 & 50 \\
\hline Inoculum output/Seawater input period & $\mathrm{h}$ & 2 & 4 \\
\hline \multicolumn{4}{|l|}{ System water and power } \\
\hline Inoculum output & $\mathrm{m}^{3} \mathrm{ha}^{-1} \mathrm{~d}^{-1}$ & 672 & 647 \\
\hline Seawater input & $\mathrm{m}^{3} \mathrm{ha}^{-1} \mathrm{~d}^{-1}$ & 672 & 696 \\
\hline Total Recirculation power & $\mathrm{kWh} \mathrm{ha} \mathrm{d}^{-1}$ & 229 & 199 \\
\hline Total Seawater input power & $\mathrm{kWh} h \mathrm{~h}^{-1} \mathrm{~d}^{-1}$ & - & 79 \\
\hline Total Inoculum output power & $\mathrm{kWh} h \mathrm{~h}^{-1} \mathrm{~d}^{-1}$ & - & - \\
\hline Total Power & $\mathrm{kWh} \mathrm{ha}^{-1} \mathrm{~d}^{-1}$ & 229 & 278 \\
\hline
\end{tabular}

144 diameter apart, so that cultures are illuminated from below as well as from above, substantially enhancing

145 the direct light that is captured $[44,46]$. In typical deployment, the PBR is dismantled, re-installed, and 
readied for inoculation by two persons in a day. Allowing one week for the culture to scale up after inoculation, PBRs are designed to be in full production for 31 of every 32 weeks, an operating capacity of $97 \%$.

Algae culture occupies $90 \%$ of the PBR volume; the remaining $10 \%$ is an air-space continuously filled by the airlift and maintained by back-pressure sufficient to provide turgidity to the reactor. Evaporation from closed photobioreactors is generally negligible [47]; in this design, with only a single vent, most water vapor condenses on the exposed inner tube surface and rejoins the culture. The hydrodynamics are best approximated by open channel flow in a partially filled pipe [48]. The PBR is designed to be operated at $\mathrm{Re} \cong 50,000$, which corresponds to the bulk turbulence necessary to maintain homogeneous suspensions of most algal strains. Under ambient conditions at KDF, where temperature in the PBR typically ranges from $18^{\circ} \mathrm{C}$ at night to $>30^{\circ} \mathrm{C}$ in the day, the kinematic viscosity decreases significantly, directly increasing Re by $>30 \%$ during daytime (Table 2). Oxygen concentration, which can reach $>500 \%$ saturation at moderately high productivity in open raceway ponds, significantly inhibiting photosynthesis $[49,50]$, does not rise to $>150 \%$ saturation in these PBRs under comparable conditions [43]. A process control system monitors and controls $\mathrm{pH}$ at 8.1, supplying $\mathrm{CO}_{2}$ on demand by injection into the airlift "down-comer," which provides a counter-current dissolution system with $90 \%$ efficiency. At a fluid velocity of $0.40 \mathrm{~m} \mathrm{~s}^{-1}$, the cycle time between successive injections of $\mathrm{CO}_{2}$ to the culture is about $10 \mathrm{~min}$ (Table 2); at a typical productivity of $25 \mathrm{~g} \mathrm{~m}^{-2} \mathrm{~d}^{-1}$, the $\mathrm{pH}$ deviates by \pm 0.05 between injections. Temperature is monitored but not controlled.

PBRs are operated as a semi-continuous culture, each yielding $12.5 \mathrm{~m}^{3}$ of inoculum daily at a doubling rate of $1 \mathrm{~d}^{-1}$. Cultures are harvested from PBRs at sunset, with volumes transferred by gravity to ponds on a terrace below. After harvest, the PBRs are refilled with dilute medium made on demand from freshly filtered, UV-treated seawater via the central process control system, which monitors flows and controls actuated valves. Energy use by PBRs is primarily for continuous recirculation, driven by a lowpressure, high volume airlift with an efficiency of $25 \%$ (as determined by Beal et al.[1]), which is lower than the estimate of $39-45 \%$ for other air-lift tubular PBRs [14, 44]. Energy for recirculation is $4.25 \mathrm{kWh}$ 
$172 \mathrm{~d}^{-1}$ for each KDF PBR, or, for each hectare dedicated to PBRs, $229 \mathrm{kWh} \mathrm{ha}^{-1} \mathrm{~d}^{-1}$, not including pumping 173 and pre-treatment of seawater (Table 2).

Ponds are of the recirculating open raceway type (Table 3), with berms constructed of native soil

175 and a hardening additive, and covered with a smooth, easily-cleaned, 20-year warrantied liner

176 (Hypalon ${ }^{\circledR}$ ) overlaid on geotextile (Manning's $\mathrm{n}=0.010$ ). The six ponds at KDF are each $400 \mathrm{~m}^{2}$ in

177 lighted surface area, and $60 \mathrm{~m}^{3}$ in volume. The paddlewheel in KDF ponds is partially submerged - to

178 improve efficiency - in a 40-cm deep sump at one end of the pond that is also used for carbonation and

179 harvesting. To conserve water and reduce fluid transfer volumes, ponds are designed to operate at an

180 average culture depth of $0.15 \mathrm{~m}$.

181 Though open ponds are often operated at greater depths [11], which conserves energy for paddlewheels

182 [51], we found in KDF trials that overall performance at $0.15 \mathrm{~m}$ depth compared favorably with that at 1830.20 and $0.30 \mathrm{~m}$, with no significant change in areal productivity. The preferred turbulence regime is 184 species-dependent, and can be determined empirically. A variable-speed motor on the paddlewheel 185 delivers a dynamic range of turbulence, up to $\operatorname{Re}>250,000$; lead candidate strains we have tested in ponds 186 so far perform best at $\mathrm{Re}>50,000$ (Table 3). The process control system supplies $\mathrm{CO}_{2}$ on demand to a 187 diffuser system immersed in the sump so that, at a fluid velocity of $0.40 \mathrm{~m} \mathrm{~s}^{-1}$ and a cycle time of $7 \mathrm{~min}$ 188 (Table 3), $\mathrm{pH}$ can be maintained at $8.1 \pm 0.05$ given a pond productivity of $25 \mathrm{~g} \mathrm{~m}^{-2} \mathrm{~d}^{-1}$. Temperature is 189 monitored but not controlled. Annually averaged pan evaporation of $4.2 \pm 1.3 \mathrm{~mm} \mathrm{~d}^{-1}$, equivalent to a loss 190 of $2.8 \% \mathrm{~d}^{-1}$ in a $15-\mathrm{cm}$ deep pond, was estimated using the Penman-Monteith equation [52] based on 474 191 continuous days of hourly meteorological measurements at KDF [53] just preceding the demonstration 192 period described here (Fig A-1; SI). Energy requirements depend strongly on the efficiency of the pond 193 recirculation device. Overall paddlewheel efficiency in open raceway ponds has been estimated in the 194 range from $10 \%$ to $64 \%[11,54-56]$; we assume a conservative value of $\sim 10 \%$ [56]. 
Table 3 Physical design parameters of open raceway ponds. Seawater process power of 91 and $11 \mathrm{kWh}$

$196 \mathrm{ha}^{-1} \mathrm{~d}^{-1}$ for 1-d and 2-d ponds is for Hawaii, increasing to 406 and $47 \mathrm{kWh} \mathrm{ha}^{-1} \mathrm{~d}^{-1}$ in Texas.

\begin{tabular}{|c|c|c|c|c|}
\hline Design Parameter & Units & Actual & $\begin{array}{c}\text { Base Case: } \\
\text { 1-day } \\
\text { ponds } \\
\end{array}$ & $\begin{array}{c}\text { Base Case: } \\
\text { 2-day } \\
\text { ponds } \\
\end{array}$ \\
\hline \multicolumn{5}{|l|}{ Unit Dimensions } \\
\hline Length & $\mathrm{m}$ & 80 & 347 & \\
\hline Depth & $\mathrm{m}$ & 0.15 & 0.15 & \\
\hline Width & $\mathrm{m}$ & 5.3 & 31.0 & \\
\hline Land area & $\mathrm{m}^{2}$ & 421 & 10,634 & \\
\hline Culture surface area & $\mathrm{m}^{2}$ & 400 & 10,000 & \\
\hline Culture volume & $\mathrm{m}^{3}$ & 60 & 1500 & \\
\hline Carbonation sump depth & $\mathrm{m}$ & - & 1.8 & \\
\hline Hydraulic radius & $\mathrm{m}$ & 0.134 & 0.147 & \\
\hline Fluid velocity & $\mathrm{m} \mathrm{s}^{-1}$ & 0.40 & 0.40 & \\
\hline Cycle time & $\min$ & 6.7 & 28.3 & \\
\hline Reynolds number@18 $18^{\circ} \mathrm{C}$ & & 48,500 & 53,200 & \\
\hline Reynolds number@30 $\mathrm{C}$ & & 63,900 & 70,100 & \\
\hline Hydraulic power & $\mathrm{W}$ & 105 & 1,822 & \\
\hline Paddlewheel/Airlift efficiency & & 0.10 & 0.25 & \\
\hline Unit Recirculation power & $\mathrm{kWh} \mathrm{d}^{-1}$ & 25 & 175 & \\
\hline Residence time & $\mathrm{d}$ & 1 to 4 & 1 & 2 \\
\hline Seawater:inoculum & $\mathrm{m}^{3} \mathrm{~m}^{-3}$ & 1 & 1 & 1 \\
\hline Seawater input or Harvest period & $\mathrm{h}$ & 2 & 4 & 4 \\
\hline \multicolumn{5}{|l|}{ System water and power } \\
\hline Seawater input & $\mathrm{m}^{3} h \mathrm{~h}^{-1} \mathrm{~d}^{-1}$ & & 777 & 212 \\
\hline Evaporation & $\mathrm{m}^{3} \mathrm{ha}^{-1} \mathrm{~d}^{-1}$ & 42 & 42 & 42 \\
\hline Inoculum output & $\mathrm{m}^{3} h \mathrm{a}^{-1} \mathrm{~d}^{-1}$ & & 1,458 & - \\
\hline Process water output & $\mathrm{m}^{3} h \mathrm{~h}^{-1} \mathrm{~d}^{-1}$ & & - & 713 \\
\hline Total Recirculation power & $\mathrm{kWh} \mathrm{ha}^{-1} \mathrm{~d}^{-1}$ & 937 & 163 & 163 \\
\hline Total Seawater process power & kWh ha ${ }^{-1} \mathrm{~d}^{-1}$ & - & 91 & 11 \\
\hline Total Power & $\mathrm{kWh} \mathrm{ha} \mathrm{d}^{-1} \mathrm{~d}^{-1}$ & 937 & 254 & 174 \\
\hline
\end{tabular}

Ponds are operated as batch cultures. After sunset the empty pond is partially filled with fresh,

199 unfiltered seawater. Concentrated nutrients are added, and fresh medium is allowed several hours to

200 equilibrate with atmospheric temperature. Ponds are inoculated with PBR culture, cultivated for periods

201 of 1 to 3 days, and harvested after nutrients have been depleted to undetectable levels from the medium. 
The first stage of harvesting takes advantage of the natural process of aggregation and sinking that is well known among marine diatoms and many other marine microalgae [57]. Such aggregates typically form after post-bloom nutrient exhaustion; observed sinking rates can exceed $1 \mathrm{~m} \mathrm{~h}^{-1}[58,59]$. The two strains selected for this study exhibit high sinking rates, order $1 \mathrm{~m} \mathrm{~h}^{-1}$, after nutrient exhaustion under production conditions. The harvesting process uses the open pond as a first-stage settling tank. On the day of harvest,

207 just before sunset, paddlewheels are turned off, and algal aggregates settle to the bottom within $<1 \mathrm{~h}$.

208 Supernatant is then removed through a standpipe, located in the sump, with its intake at the level of the 209 raceway bottom, making it possible to gently remove $95 \%$ of the spent culture medium while leaving the 210 algal biomass concentrated in a thin film of water over the entire raceway. Spent medium is returned to 211 the ocean via a percolation field. The standpipe is removed from the sump, which is drained to a 212 secondary settling tank while harvesting is completed. The concentrated algal biomass remaining on the 213 raceway bottom is harvested by a team of two persons using power washers to move it along each 214 raceway toward the sump, which requires 10-12 min. When harvest is complete, the pond is clean and 215 ready to be re-inoculated. Several hours later, the secondary settling tank yields a biomass concentrate of $216>1 \%$ total suspended solids (TSS), a feedstock requirement for the Westphalia disk-stack centrifuge used 217 for subsequent processing to yield a dewatered end product of 20\%-30\% TSS.

\subsection{Large-scale production}

The goal of both Staurosira and Desmodesmus production trials was to evaluate the impact of

220 two independent variables - (i) initial total N, or the sum of particulate organic nitrogen $\left(\mathrm{PON}_{i}\right)$ and

221 dissolved inorganic nitrogen $\left(\mathrm{DIN}_{i}\right)$, at pond inoculation and (ii) the initial "Fertilizer Ratio" at

222 inoculation, $\mathrm{DIN}_{i} / \mathrm{PON}_{i}$ - on pond yield. We also compared yield over 2-day vs. 3-day production runs.

223 The initial total $\mathrm{N}\left(\mathrm{TN}_{i}\right)$ at pond inoculation was varied from 500 to 2,100 $\mu \mathrm{mol}$ for Staurosira, and up to

$2242,600 \mu \mathrm{mol}$ for Desmodesmus. The initial Fertilizer Ratio was varied from 0 to $\sim 3.8$. Another goal of the 225 Desmodesmus trials was to evaluate the impact of removing silicate as a required nutrient. 
Staurosira and Desmodesmus were first scaled up in 200-L reactors $(\sim 5 \mathrm{~d})$ and $25-\mathrm{m}^{3}$ PBRs $(\sim 10$

227 d) until three PBR cultures reached maximum productivity, when they began to be harvested routinely at

$22850 \%$ per day to inoculate one pond per day. Ponds were harvested at sunset of day 3 , so three ponds were

229 continuously in operation. We conducted 110 production runs with Staurosira (Apr 4 to Jul 28, 2010) and

$230>60$ with Desmodesmus (Apr 28 to Jul 26, 2011), using silicate for the diatom and $\mathrm{NO}_{3}$ as the nitrogen

231 source. PBR cultures were grown in $\mathrm{f} / 2$. Comprehensive data sets were not available for all production

232 runs; Desmodesmus production run data are supplemented with results from 31 simulations at mid-scale.

Meteorological data, including photosynthetically active radiation (PAR), were collected using a

234 Davis VantagePro2 weather station on site and archived as hourly averages (Figs A2-4; SI). In addition to

235 continuous in-pond temperature and $\mathrm{pH}$, other measurements (Table 1) were made for PBRs sampled

236 daily, before and after harvest, and ponds sampled at least twice daily, either at 08.00 and 16.00 or at

237 sunrise and sunset. All measured concentrations of nutrients and biochemical content in ponds (Table 1)

238 were expressed in units of $\left[\mathrm{g} \mathrm{m}^{-2}\right]$ of pond culture surface area. Protein plus nucleic acid content was

239 calculated from PON using the Kjeldahl ratio of 6.25 and assuming a nucleic acid content of 5\% ash-free

240 dry weight (AFW) [60], and carbohydrate content was calculated by difference. Sinking index was

241 measured daily in late afternoon samples using the graduated cylinder method. All ponds were harvested

242 after 3 days of batch culture by gravitational settling, and were required to meet dual standards of $<5 \%$

243 loss of biomass and undetectable DIN concentrations in supernatant process water.

247 differences between the KDF and the Base Case facility are as follows:

Terraced site: The 100-ha Base Case is designed in terraces on a natural 1\% slope, which enables

249 volume transfers by gravity and reuse of culture medium for a period of about two weeks. This residence time regulates salinity and effectively avoids contamination by invasive species. 
source. Nitrogen and phosphorus are provided as ammonia and di-ammonium phosphate (DAP).

254 polyethylene tubing to $490 \mathrm{~m}$, which adds little to the cost and delivers the same recirculating turbulent

255 régime at a relatively lower energy demand (Table 2). Gas exchange is facilitated through the $10 \%$ head

256 space in each PBR, as described for the KDF design above. PBRs provide a total culture volume of 1,344

$257 \mathrm{~m}^{3} \mathrm{ha}^{-1}$ land area.

Pond size: Open ponds are increased to 1.0 ha in area (Table 3), equal to the largest ponds in sustained commercial operation [54]; otherwise, the hydrodynamics are very similar. Ponds provide a 260 total culture volume of $1,411 \mathrm{~m}^{3} \mathrm{ha}^{-1}$ land area.

Pond liner and recirculation: Pond liner is reinforced polypropylene, chosen based on our

262 assessment of cost, durability, and effects on live algal cultures of more than a dozen materials [61].

263 Ponds are driven by a single airlift in a countercurrent carbonation sump, similar in all respects to the 264 baffle design of Lundquist [11], except that air is injected at the base of the riser to provide bulk flow, 265 replacing the need for a paddlewheel. Airlift-driven raceways have reported power efficiencies of $>40 \%$ $266[14,44,62]$; however, in their Appendix A, Beal et al. [1] determined an efficiency for this design to be

$26725 \%$ (Table 3). The airlift has no moving parts, is easier to install and, when combined with the 268 carbonation sump, provides a more effective process for gas exchange than the less efficient paddlewheel. Pond types: Ponds are designed for batch cultures of two types: 1-day ponds are inoculated from

270 PBRs and emptied daily to inoculate 2-day ponds. Both pond types are of the same design and 271 construction, except that 2-day ponds also serve as settling basins during final harvesting. Harvesting and dewatering: Gravitational settling combined with the filter press produces an end

273 product of $20 \%$ TSS. This process compares favorably with other harvesting and dewatering routes we 274 evaluated in large-scale trials, including, for primary harvesting, flocculation by chemical- or auto275 induced $\mathrm{pH}$ increase [63], induced air flotation [64], and the use of chemical flocculants; and, for 
dewatering, solar drying or disk-stack centrifugation using a Westfalia separator ( model MSD 300-96-

277 777).

\subsection{Base Case capital cost}

The Base Case capital cost estimate is for a 111-ha turn-key facility, built to a cost accuracy of

$280 \pm 20 \%$ using estimation methods described in Beal et al. [1]. In this paper we present the same costs, but

281 categorized differently to assist readers evaluating cultivation-specific results. Major categories in this

282 analysis include, site preparation, systems for harvesting and cultivation (scale-up, PBRs, and open

283 ponds), and subsystems for onsite delivery of power, $\mathrm{CO}_{2}$, air, seawater pre-treatment, storage and

284 delivery of nutrients, and process control. Offsite delivery systems for $\mathrm{CO}_{2}$ and seawater, and all onsite

285 production systems, which occupy $95 \%$ of the facility, have been designed and specified in sufficient

286 detail to proceed to the first set of construction drawings. We include the costs of processing facilities for

287 Case 4 in Beal et al. [1] to enable comprehensive comparison to published cost estimates for other end-to288 end pathways.

\section{2. Results}

\subsection{Actual system performance}

Here we quantify, for both Staurosira and Desmodesmus, the effects of initial total $\mathrm{N}$ and the

292 Fertilizer Ratio on the yield of all key biochemical fractions and, at the same time compare the

293 performance of 2-day vs 3-day ponds. The overarching measure of performance is the yield of biomass,

294 lipid, and other products, with the additional requirement that DIN is absent from the culture medium at 295 the time of harvest. These results inform key operational aspects of the Base Case system design.

\subsubsection{Effects of initial total nitrogen $\left(T N_{i}\right)$ on yield}

Yield was greater at higher nitrogen levels. For both Staurosira and Desmodesmus the yields of

298 lipid, protein, and dry weight increased substantially as a function of $\mathrm{TN}_{i}$ over the range tested, with the 299 most favorable results achieved in 2-day ponds (Fig. 2). At a given level of $\mathrm{TN}_{i}$ both species yielded the 300 same amount of protein, and similar amounts of lipid, but Staurosira produced significantly more dry 
weight, reflecting its greater ash content. In the range tested, from 0.8 to $4.2 \mathrm{~g} \mathrm{~m}^{-2} \mathrm{TN}_{i}$, lipid yield from

Staurosira almost doubled while protein yield increased five-fold. Desmodesmus showed comparable increases in lipid and protein as a function of $\mathrm{TN}_{i}$. before harvest, as observed in mid-scale bag cultures (Fig 1). Likewise, concentrations of $\mathrm{PO}_{4}$ and, for diatoms, $\mathrm{Si}(\mathrm{OH})_{4}$, were also reduced to undetectable levels. Thus, inoculum from PBR cultures contained

308 N, P and Si only in particulate form.

The Base Case design requires that DIN concentrations in final production ponds are reduced to zero in discharged culture medium at the time of harvest. Furthermore, it makes the assumption that nitrogen is conserved. In other words, all DIN is converted to PON, and no nitrogen is discharged as $\mathrm{N}_{2} \mathrm{O}$.

312 Our results validate these assumptions.

In open pond cultures dissolved nitrogen was entirely converted to particulate form in $<2 \mathrm{~d}$ at all

314 initial total $\mathrm{N}$ concentrations of up to $4.2 \mathrm{~g} \mathrm{~m}^{-2}$, or $2.0 \mathrm{mmol} \mathrm{N}$, for both Staurosira (Fig $3 \mathrm{~A}-\mathrm{F}$ ) and

315 Desmodesmus (Fig 4 A-F) for all ponds with a Fertilizer Ratio of $<2.0$ (Fig 5). At the same time,

316 concentrations of DIN were undetectable in ponds after $2 \mathrm{~d}$ (Figs 2D, 3D), as were those of $\mathrm{HPO}_{4}$ and

$317 \mathrm{Si}(\mathrm{OH})_{4}$, indicating that all DIN was fully incorporated into PON.

318 Independent studies of Staurosira pond cultures at KDF showed that the net flux of $\mathrm{N}_{2} \mathrm{O}$ was into 319 the ponds [65], not into the atmosphere [66], so after $2 \mathrm{~d}$ all initial $\mathrm{N}$ should have been present at PON. 320 We found this to be the case for Desmodesmus (Fig 4). However, the apparent conversion of $\mathrm{NO}_{3}-\mathrm{N}$ to 321 PON in Staurosira cultures was only 0.95 in 2-d ponds and 0.87 in 3-d ponds (Fig 3 D, F). We attribute 322 this apparent loss of $\mathrm{N}$ to a sampling artifact caused by settling and attachment to the pond liner. The 323 measured slopes thus indicate settling errors of 5\% on Day 2 and $13 \%$ on Day 3. Subsequent studies at 324 KDF to quantify the "settling error" in Staurosira observed it rising up to 50\% by Day 4. We conclude 325 that in a 2-day pond culture period all nutrients are converted to particulate form, leaving none dissolved 326 in the spent medium. 
If all initial dissolved nitrogen, $\mathrm{DIN}_{i}$, is converted to particulate form at harvest we have:

$$
P O N_{f}=P O N_{i}+D I N_{i}
$$

where $\mathrm{PON}_{i}$ and $\mathrm{PON}_{f}$ are the initial and final concentrations of particulate nitrogen, respectively.

331 Dividing by $\mathrm{PON}_{i}$, the absolute rate of increase in PON over a given period can be expressed as a 332 function of the Fertilizer Ratio:

$$
\frac{P O N_{f}}{P O N_{i}}=\frac{D I N_{i}}{P O N_{i}}+1
$$

and thus the doubling rate of PON, $\mu_{N}$, can be expressed as

$$
\mu_{N}==\left[\ln \left(\frac{D I N_{i}}{P O N_{i}}+1\right)\right] / t
$$

where $t$ is the open pond culture period in days.

Actual performance of 2-day pond cultures shows that the doubling rate of PON increased according to equation (3) until the Fertilizer Ratio attained a value of $\sim 2.0$, with no apparent difference between species (Fig. 5). The Desmodesmus cultures inoculated at Fertilizer Ratios $>2.0$ did not attain the expected doubling rate of PON, reflecting the fact that after 2 days these were the only cultures that still contained significant DIN (Fig. 4). These results quantitatively inform the Base Case design: at $\mathrm{TN}_{i}$ values up to $4.2 \mathrm{~g} \mathrm{~m}^{-2}$, a Fertilizer Ratio of 2.0 yields a PON doubling rate of $0.55 \mathrm{~d}^{-1}$; importantly, these values also dictate the amount of particulate inoculum required and thus affect the ratio of PBRs to ponds.

\subsubsection{Effects of initial total nitrogen and Fertilizer Ratio on the C:N ratio}

To illustrate the effects of nitrogen fertilization in the present data set, we consider two cases for total nitrogen: (i) a "Low N" case of $1.85 \mathrm{~g} \mathrm{~m}^{-2} \mathrm{TN}_{i}$, roughly equivalent to $f / 2$ medium, and (ii) a "High N" case of $4.2 \mathrm{~g} \mathrm{~m}^{-2} \mathrm{TN}_{i}$, the apparent upper limit of full conversion of DIN to PON in 2-day ponds (Figs environment. 
respectively. This initial uniformity, which attests to the high biochemical consistency of inoculum produced by PBRs, rapidly changed as a result of both total $\mathrm{TN}_{i}$ and the Fertilizer Ratio. By the time of harvest on Day 2, for the Low N case, the C:N ratio rose to 11.5 and 11.0 for Staurosira and Desmodesmus, respectively. By comparison, for the High N case, the C:N ratio rose to 8.5 and 7.7 (Figs 6A, 7A), respectively. It is clear that cultures deprived of $\mathrm{N}$ continued to fix $\mathrm{C}$. Consequently, cultures with less initial $\mathrm{N}$ were deprived sooner, fixed only $\mathrm{C}$ for a longer period, and thus their $\mathrm{C}: \mathrm{N}$ ratios were greater. These same trends continued on Day 3, with further increases in the C:N ratio for both strains in both cases.

A low Fertilizer Ratio also led to a high $\mathrm{C}: \mathrm{N}$ ratio at harvest for both strains, again showing that cultures relatively deprived of $\mathrm{N}$ developed the greatest $\mathrm{C}: \mathrm{N}$ ratios (Figs 6B, 7B). At a Fertilizer Ratio $>2$ there was no apparent effect on the $\mathrm{C}: \mathrm{N}$ ratio. The combination of low total nitrogen and a low Fertilizer Ratio led to the highest C:N ratios.

\subsubsection{Constant mass relationships}

Relationships of POC and DW to AFW, and POC to DW, were constant within species on the with a lower DW:AFW ratio of $1.028\left(r^{2}=0.99\right.$; Fig 9A), corresponding to only $2.7 \%$ ash; measurements

\subsubsection{Effect of pond duration on lipid and protein yield}

At the time of inoculation, for both Staurosira and Desmodesmus cultures, the lipid content $\left[\mathrm{g} \mathrm{g}^{-1}\right.$ AFW] was virtually uniform at 38\% AFW $\left(r^{2}=0.82\right.$; Fig B-3: SI $)$ and 47\% AFW ( $r^{2}=0.0 .78$; Fig B-4: SI), respectively. The protein content was not only uniform but also similar for both species, at $47 \%\left(r^{2}=0.91\right.$;

377 SI: Fig B-5) and 46\% ( $r^{2}=0.93$; SI: Fig B-6), respectively. 

3 , achieving the highest values for both species at high $\mathrm{TN}_{i}$. The relative increase in lipid was greater on Day 2 than on Day 3 for both species (Fig 10). By comparison, the protein yield reached a maximum by harvest time on Day 2, and did not increase on Day 3 (Fig 11), reflecting the depletion of DIN to zero.

Taken together, the foregoing results provide a clear illustration of the interwoven dynamics of $\mathrm{C}$, $\mathrm{N}$, protein, and lipid. After all DIN is converted to protein, the continued fixation of C leads, for

384 Staurosira and Desmodesmus, to a continued increase in lipid synthesis. The sooner a culture

385 has depleted the available DIN, the greater will be its $\mathrm{C}: \mathrm{N}$ ratio and lipid content after the same amount of 386 time. Under all conditions tested, daily averaged protein yield was clearly greater in 2-d vs 3-d ponds. In the following summary we provide the complete mass balance for Staurosira and Desmodesmus for both Low $\mathrm{N}$ and High $\mathrm{N}$ cases, allowing a broader evaluation of 2-d vs 3-d ponds.

\subsubsection{Effects of $N$ fertilization: a summary}

Here we compare the average daily productivity and annually averaged yield of all key

biochemical constituents as a function of $\mathrm{N}$ fertilization in both 2-d and 3-d ponds based on the foregoing a value of $4.2 \mathrm{~g} \mathrm{~m}^{-2} \mathrm{TN}_{i}$ for the High $\mathrm{N}$ case, we calculated the yields of DW, AFW, lipid, and protein on after 2 days (Fig 5). Knowing that $1.8 \mathrm{~g} \mathrm{~m}^{-2} \mathrm{TN}_{i}$ at inoculation will yield $1.8 \mathrm{~g} \mathrm{~m}^{-2} \mathrm{PON}$ at the time of harvest (Figs 3,4), we estimated the yield of POC from the C:N ratio in at the time of harvest in both 2-d and 3-d ponds for Staurosira (Fig 6A) and Desmodesmus (Fig 7A). So, for example, from regression lines shown in Fig $6 \mathrm{~A}$ it can be seen that a pond inoculated at $1.8 \mathrm{~g} \mathrm{~m}^{-2} \mathrm{TN}_{i}$ has a C:N ratio $\left[\mathrm{g} \mathrm{g}^{-1}\right]$ of 11.5 after

$401 \mathrm{gC} \mathrm{gN}^{-1}=20.7 \mathrm{~g} \mathrm{~m}^{-2} \mathrm{C}$, and the yield from a 3-d pond is $25.2 \mathrm{~g} \mathrm{~m}^{-2} \mathrm{C}$. For the High $\mathrm{N}$ case of $4.2 \mathrm{~g} \mathrm{~m}^{-2} \mathrm{~N}$, regression lines in Fig 6A show a C:N ratio of 8.5 after 2-d and 10.0 after 3-d, so the yields of POC are

$403 \quad 35.7$ and $42.0 \mathrm{~g} \mathrm{~m}^{-2} \mathrm{C}$, respectively. 

for both species (Figs 8A, 9A), and ash was calculated by difference. For example, the C:AFW ratio of $0.562\left(r^{2}=0.94\right.$; Fig 8A) for Staurosira yields $20.7 \mathrm{~g} \mathrm{~m}^{-2} \mathrm{C} \div 0.562 \mathrm{~g} \mathrm{C} \mathrm{g} \mathrm{AFW}^{-1}=36.8 \mathrm{~g} \mathrm{~m}^{-2} \mathrm{AFW}$ for the Low N Case in 2-d ponds. Applying the AFW:DW ratio of $1.46\left(r^{2}=0.94\right.$; Fig 8A) yields $36.8 \mathrm{~g} \mathrm{~m}^{-2} \mathrm{AFW}$ $408 \times 1.46 \mathrm{~g} \mathrm{DW} \mathrm{g} \mathrm{AFW}^{-1}=53.7 \mathrm{~g} \mathrm{~m}^{-2} \mathrm{DW}$, and calculating the ash by difference we obtain $53.7 \mathrm{~g} \mathrm{~m}^{-2} \mathrm{DW}-$ $36.8 \mathrm{~g} \mathrm{~m}^{-2} \mathrm{AFW}=16.9 \mathrm{~g} \mathrm{~m}^{-2}$ ash. The corresponding lipid yields were calculated from regressions of yield measurements on $\mathrm{TN}_{i .}$ (Fig 10), which, for Staurosira in 2-d ponds, is lipid $=2.59 \mathrm{TN}_{i}+12.1$. Thus,

411 the Low $\mathrm{N}$ case yields $\left(2.59 \times 1.8 \mathrm{~g} \mathrm{~m}^{-2} \mathrm{~N}\right)+12.1=16.8 \mathrm{~g} \mathrm{~m}^{-2}$ lipid, and the High $\mathrm{N}$ case yields $23.0 \mathrm{~g}$

$412 \mathrm{~m}^{-2}$ lipid. Yields of chlorophyll, which amounted to $\sim 1 \% \mathrm{AFW}$, were calculated in the same manner based 413 on regressions provided in the supplementary information (Fig B-7, B-8). Protein yields (Fig 11) were 414 calculated using the ratio of protein:PON $=6.25[60]$ assuming complete conversion of $\mathrm{TN}_{i}$ to PON. 415 Carbohydrate content was calculated by difference by rearranging the identity: AFW $=$ protein + lipid + chlorophyll + carbohydrate. Comprehensive results of this analysis are summarized for both species for

417 the Low $\mathrm{N}$ case (Table 4) and the High $\mathrm{N}$ case (Table 5); quantitative assumptions are listed separately in table captions for each species in each case. Yield and productivity values are referenced to pond surface 419 area in $\mathrm{m}^{2}$ or ha.

The effect of nitrogen fertilization on productivity clearly shows that both species are

421 significantly less productive in the Low N Case (Table 4) than in the High N Case (Table 5). At a given 422 level of N, both species yield equal amounts of protein and similar amounts of lipid, but Staurosira 423 produces substantially more ash.

For Staurosira in the Low N case, lipid yield ranges from 26 to $31 \mathrm{MT} \mathrm{ha}^{-1} \mathrm{yr}^{-1}$ for 3-d and 2-d ponds, respectively (Table 4A); in the High $\mathrm{N}$ case, lipid yield increases significantly, from to 34 to 42 MT $\mathrm{ha}^{-1} \mathrm{yr}^{-1}$, with the greatest yield again from 2-d ponds (Table 5A). Lipid yield from Desmodesmus is slightly greater. In the Low N case, lipid yield from Desmodesmus is $32 \mathrm{MT} \mathrm{ha}^{-1} \mathrm{yr}^{-1}$ in both 2-d and 3-d 428 ponds (Table 4B). In the High $\mathrm{N}$ case, lipid yields increase to $34 \mathrm{MT} \mathrm{ha}^{-1} \mathrm{yr}^{-1}$ in $3-\mathrm{d}$ ponds and 


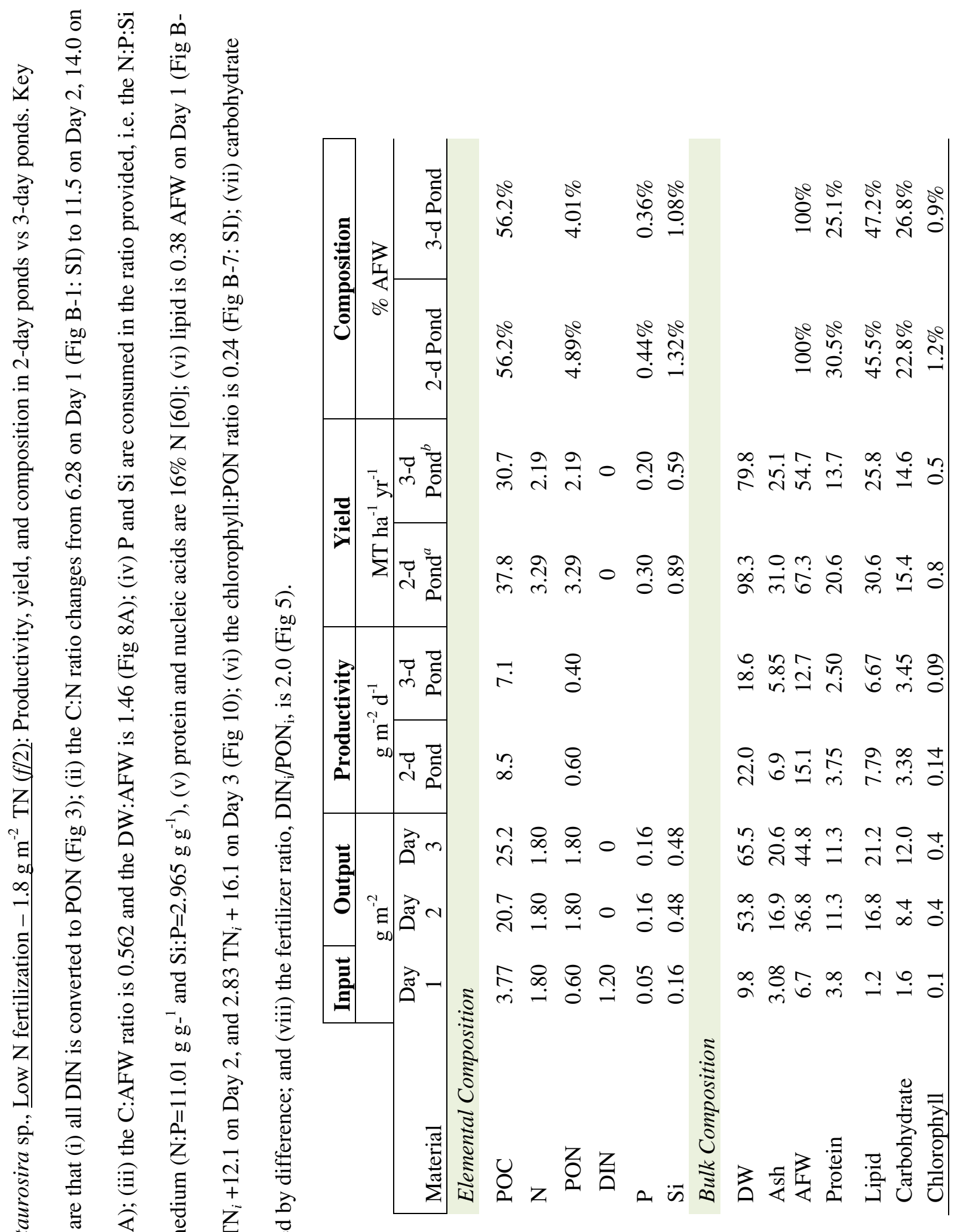




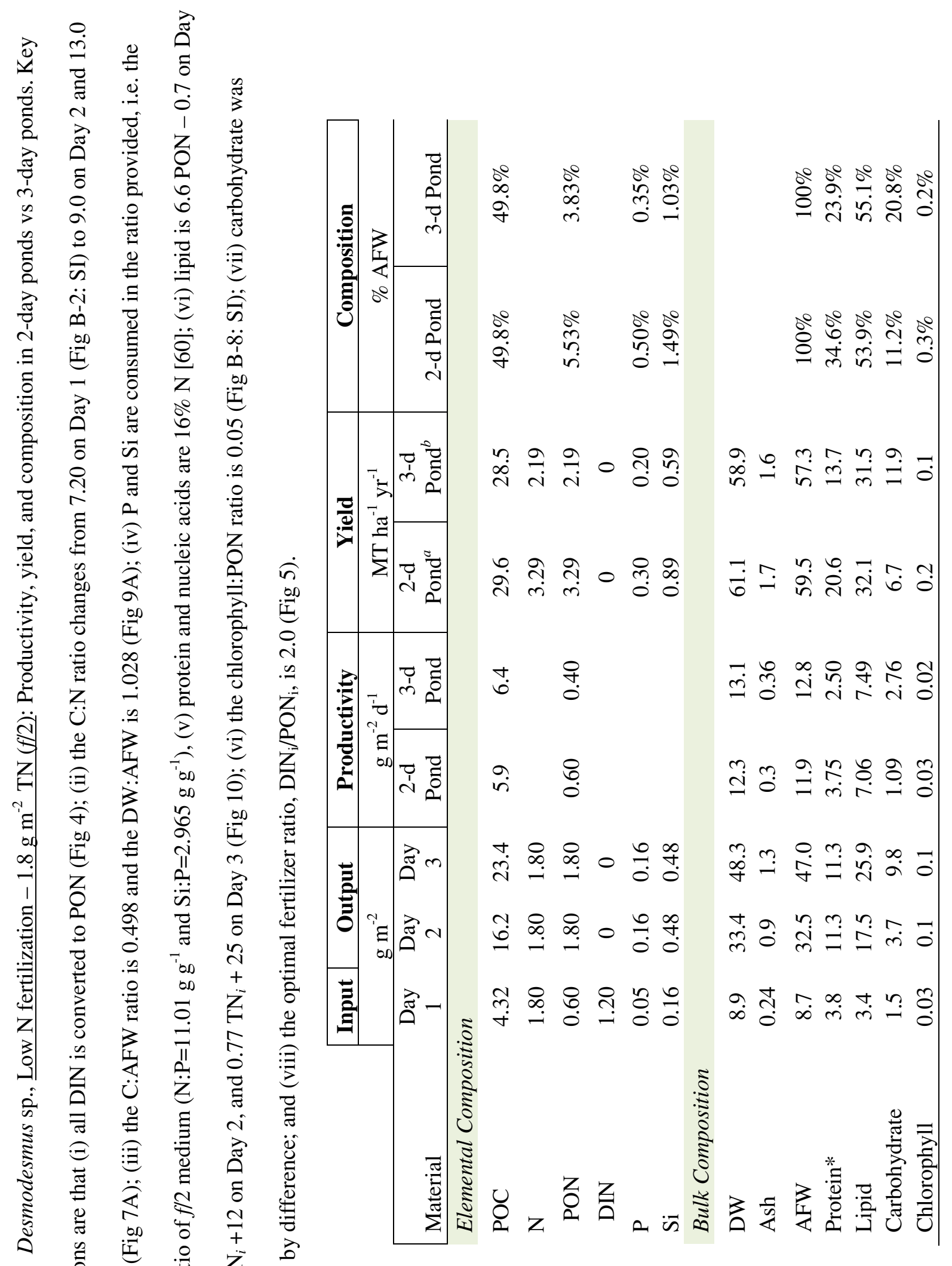




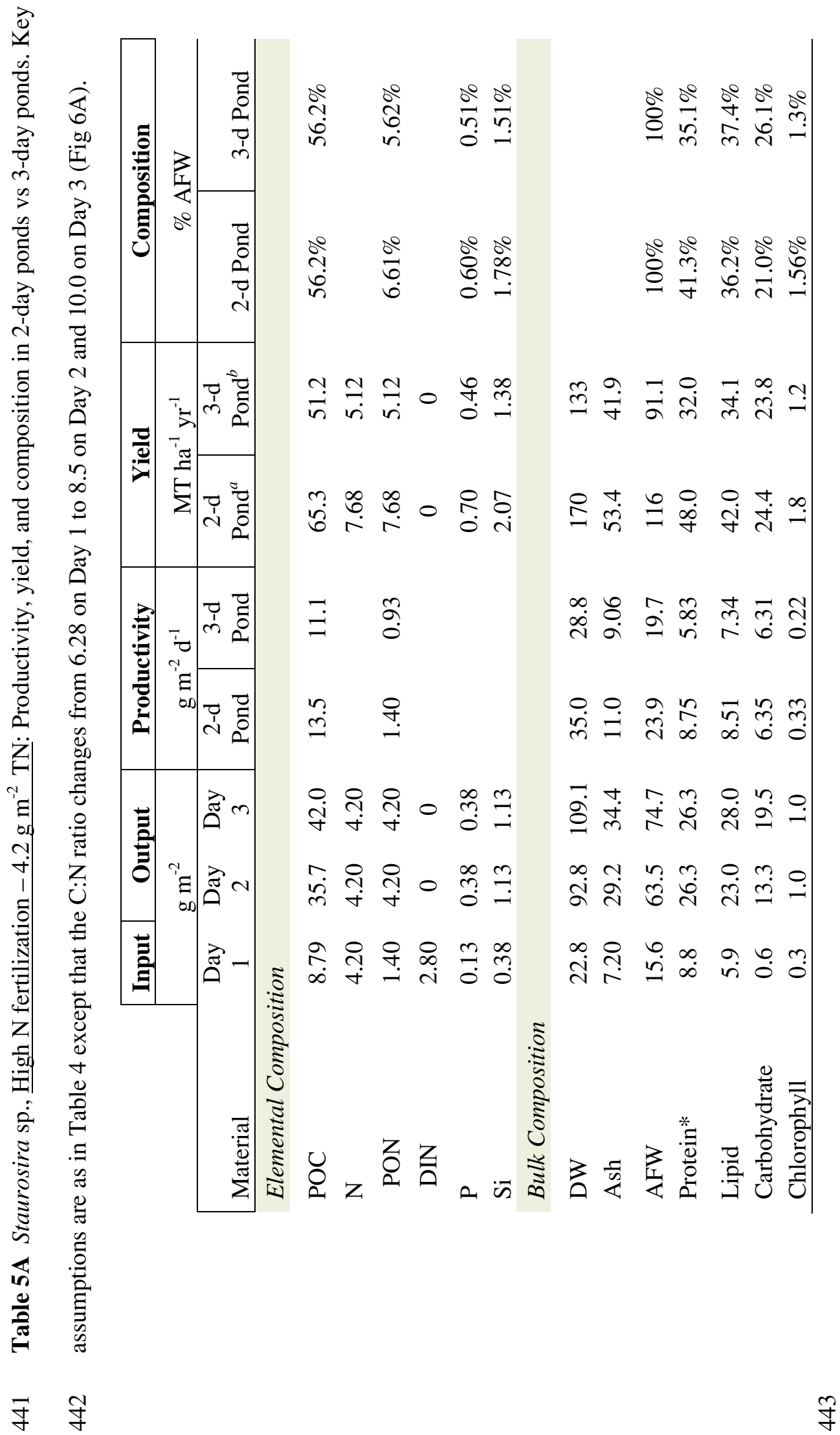




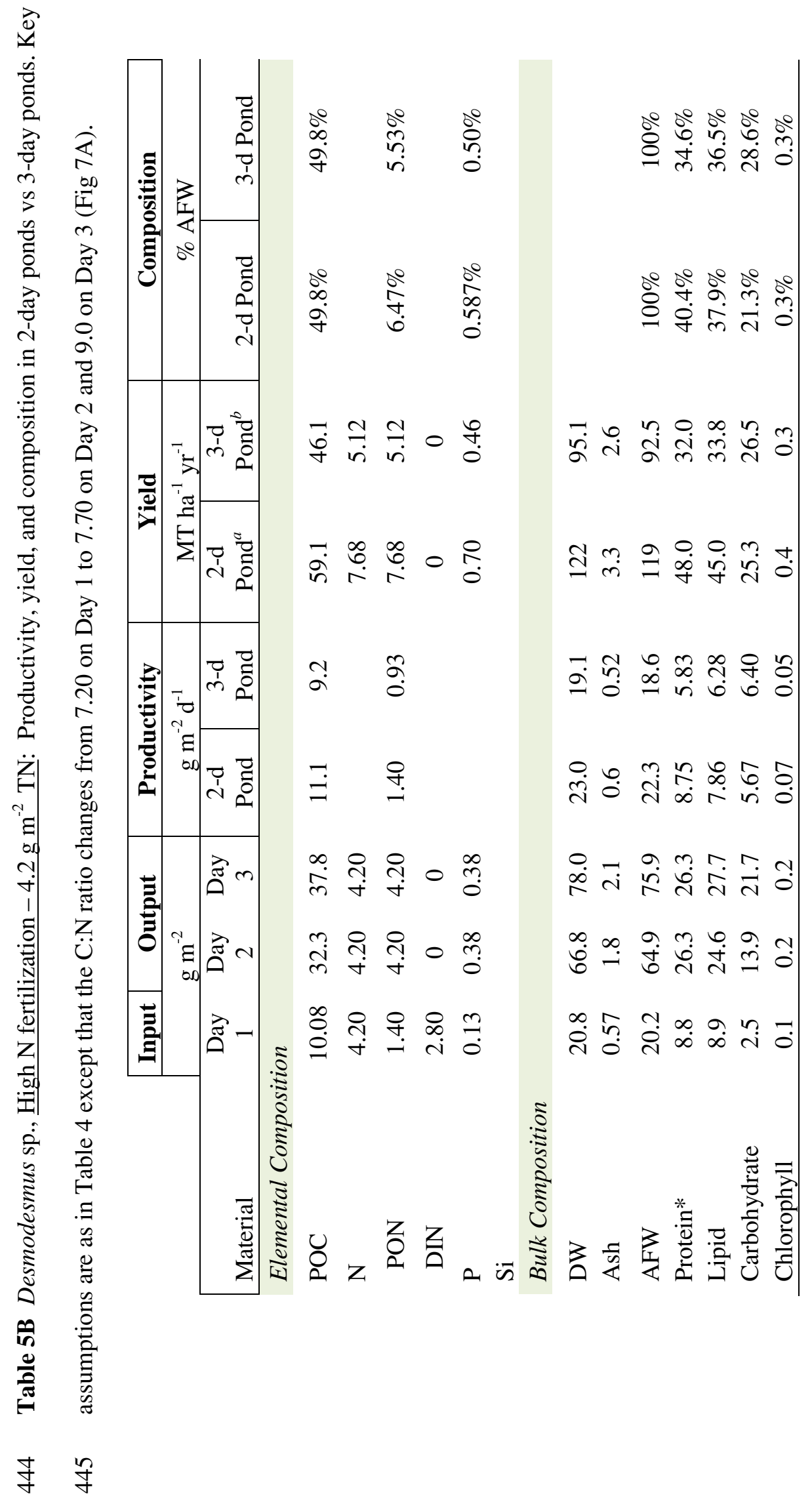


$45 \mathrm{MT} \mathrm{ha}^{-1} \mathrm{yr}^{-1}$ in 2-d ponds (Table 5B).

AFW productivity in the Low $\mathrm{N}$ case is comparable for both species: from 12.7 to $15.1 \mathrm{~g} \mathrm{~m}^{-2} \mathrm{~d}^{-1}$ for Staurosira and from 11.9 to $12.8 \mathrm{~g} \mathrm{~m}^{-2} \mathrm{~d}^{-1}$ for Desmodesmus. In the High $\mathrm{N}$ case, AFW productivity virtually doubles: from 19.7 to $23.9 \mathrm{~g} \mathrm{~m}^{-2} \mathrm{~d}^{-1}$ for Staurosira and from 18.6 to $22.3 \mathrm{~g} \mathrm{~m}^{-2} \mathrm{~d}^{-1}$ for

Desmodesmus. The highest values in both cases are from 2-day ponds, which yield 116 and $119 \mathrm{MT}^{-1}$ $\mathrm{yr}^{-1}$ for Staurosira and Desmodesmus, respectively.

Both species yield the greatest amount of protein in 2-day ponds, $48 \mathrm{MT} \mathrm{ha}^{-1} \mathrm{yr}^{-1}$ in the High $\mathrm{N}$ case, along with carbohydrate yield of $\sim 25 \mathrm{MT} \mathrm{ha}^{-1} \mathrm{yr}^{-1}$. The greatest difference between species is the amount of ash produced at these high yields: 53.4 vs. 3.3 MT ha ${ }^{-1} \mathrm{yr}^{-1}$ for Staurosira and Desmodesmus, respectively. The ash not only comes with the added cost and environmental impacts of supplying $\mathrm{Si}(\mathrm{OH})_{4}$, it also reduces the co-product value. The presence of ash in the lipid-free co-product reduces the protein content from $63 \%$ in Desmodesmus to $38 \%$ in Staurosira; for reference, the value of protein-rich feed components increases with protein content, which rises from 28 to $32 \%$ in distiller's dried grains (DDGS), to $48 \%$ in soymeal, $67 \%$ in fishmeal, and $75 \%$ in soy protein concentrate [67].

Based on the comparative performance summarized in Tables 4 and 5, a Base Case design that employs 2-d ponds for the production of Desmodesmus in the High N case is clearly indicated (Table 5B). This design produces the highest annual yields of valuable organic products combined with the lowest yield of low-value ash.

\subsection{Effect of results on Base Case design and cost}

\subsubsection{Facility configuration based on nitrogen uptake}

The facility is comprised of a series of cultivation modules, each consisting of a single 1-day pond, four 2-day ponds, and 30 PBRs, together occupying 6.4 ha; a total of 16 cultivation modules adds up to a total cultivation area of 103 ha (Table 6). There are 8 ha devoted to processing and other facilities, bringing the total facility area to 111 ha [1]. Relative areas of unit operations within the cultivation area are based on the observed doubling rate of nitrogen in 2-day ponds $\left(\mu_{N}=0.55 \mathrm{~d}^{-1}\right.$; Fig 5) and on the 
operational doubling rate of $0.69 \mathrm{~d}^{-1}$ in PBRs, assumed to be the same in 1-day ponds. Thus, the daily

472 facility production from PBRs inoculates 1-day ponds, producing 6.9 $\mathrm{MT} \mathrm{d}^{-1}$ of inoculum for 2-day

473 ponds, which in turn yield $21 \mathrm{MT} \mathrm{d}^{-1}$ AFW from the facility. $\$ 599,000$ ha $^{-1}$ for Hawaii (Table 7); the difference being driven by regional cost factors for labor and materials [68]. Thus, a 111 ha Base Case facility would cost \$59 million on the Gulf Coast, and \$67 million in Hawaii.

The cost of land preparation amounts to $\$ 34,000 \mathrm{ha}^{-1}$ for the Gulf Coast and $\$ 52,000 \mathrm{ha}^{-1}$ for Hawaii. The seawater system costs more in the Gulf Coast than Hawaii $\left(\$ 87,000\right.$ vs $\$ 5,100$ ha $\left.^{-1}\right)$ because seawater is delivered via a 5-km pipeline from the sea, rather than by a system of submersible pumps from a shallow saline aquifer. The $\mathrm{CO}_{2}$ delivery system, also using a $15-\mathrm{km}$ pipeline, is $<4 \%$ of total capex at both locations. All other costs are greater for Hawaii.

Ponds occupy $76.4 \%$ of the facility area and dominate the capital costs, ranging from $\$ 161,000$ to $\$ 251,000 \mathrm{ha}^{-1}$ of facility area, or $30 \%$ to $42 \%$ of the total, for the Gulf Coast and Hawaii, respectively. Normalized to pond surface area only, our estimate for the installed cost of a pond system ranges from $\$ 21.11$ to $\$ 32.87 \mathrm{~m}^{-2}$, comparable to the value of $\$ 34.10 \mathrm{~m}^{-2}$ for high-rate ponds in California estimated 488 by Lundquist et al [11]. The relatively low cost of PBRs is worth noting. These large-diameter reactors occupy $16 \%$ of the 490 cultivation area (Table 6), but account for $<3 \%$ of total capital (Table 7). Normalized to the PBR area 491 only (including space between PBRs), our estimate of the installed cost of a PBR system ranges from $492 \$ 6.49$ to $\$ 10.10 \mathrm{~m}^{-2}$ (Gulf Coast vs Hawaii), which is less than half the capital cost of ponds and 493 significantly lower than many other estimates. Part of the reason is the due to the materials used in this 494 design. In some designs, the entire PBR culture vessel is considered a capital expense. In our design 99\% 495 of the PBR culture vessel consists of PVC tubing that is replaced four times annually, and therefore is an 496 operating expense, detailed by Beal et al [1]. However, even when normalized to PBR area only, and 


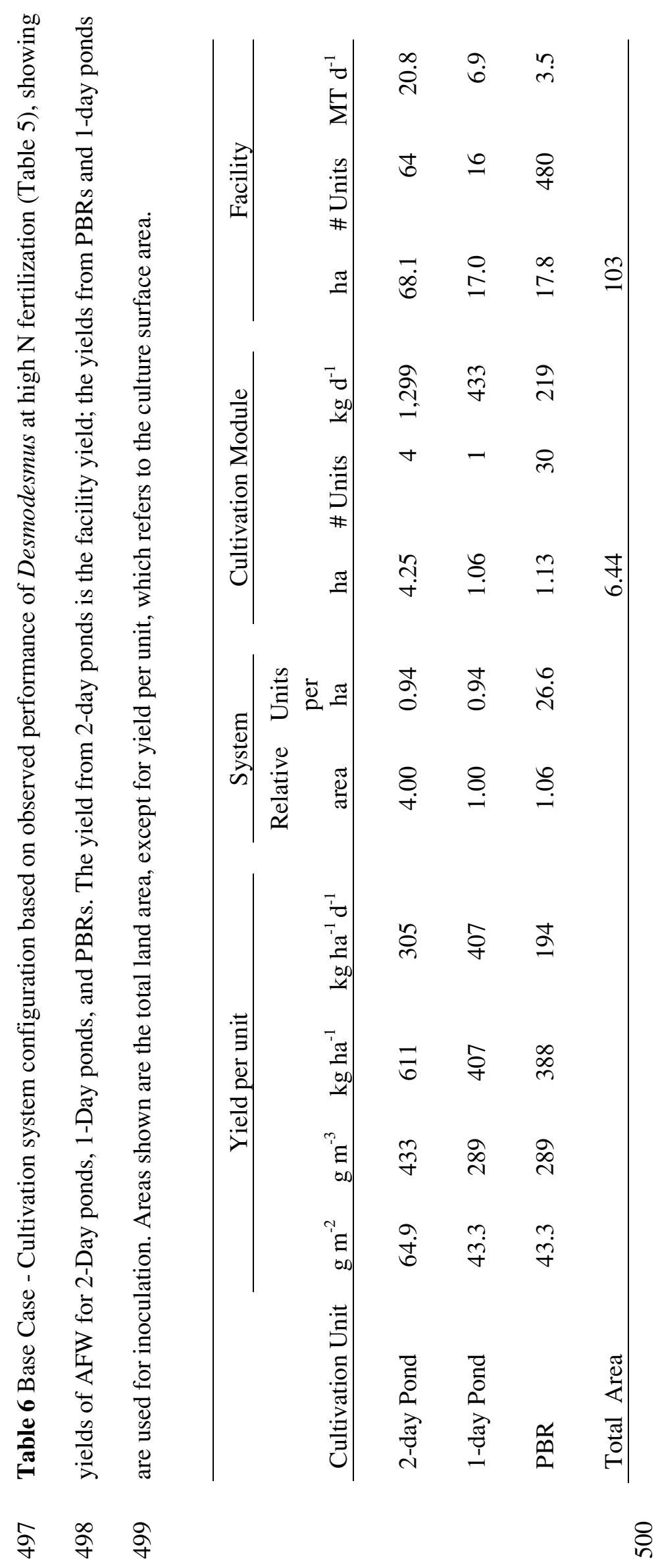


Table 7 Capital expenses, in $\$ 000$ s per hectare of total facility area, for a Base Case microalgae

502 production and processing facility of 111 ha. Land preparation: clearing, grading, trenching, pond berm

503 formation, and all mass earthmoving. Seawater system: all main supply and discharge lines to and from

504 the site, including pumps. $\mathrm{CO}_{2}$ delivery system: includes capture at the source, compression, and pipeline

505 to the facility gate. PBR system: includes the reactor itself, all internal fittings, and plumbing that

506 connects the PBR to main supply or discharge system; replaceable tubing not included. Pond system:

507 pond, pond liner, water propulsion system, valves and pumps directly connected to ponds, and pipework

508 that connects each pond to main supply or discharge system. Harvest system: clarifiers and filter press

509 equipment. Processing: equipment for Case 4 described by Beal et al. [1]. Instrumentation and control:

510 process control system and laboratory equipment. Buildings: 1 hectare under roof for warehouse storage,

511 nutrient preparation, and laboratory space. Other: nutrient mixing, air supply, scale-up culture system, and

512 other infrastructure. All costs include materials and labor.

\section{3}

\begin{tabular}{lrr}
\cline { 2 - 3 } Item & \multicolumn{2}{c}{ \$ per ha (000's) } \\
\hline Land preparation & Gulf \\
Coaii & 52.4 & 33.7 \\
Seawater system & 5.1 & 86.9 \\
CO $_{2}$ delivery & 20.5 & 13.2 \\
PBR system & 16.1 & 10.4 \\
Pond system & 251.0 & 161.2 \\
Harvest system & 25.3 & 16.3 \\
Processing & 77.2 & 49.6 \\
Instrumentation \& control & 15.5 & 10.0 \\
Electrical & 27.3 & 17.5 \\
Buildings & 72.9 & 46.8 \\
Other & 35.6 & 88.3 \\
\hline TOTAL & 599 & 534 \\
\hline
\end{tabular}

514 considered as a capital cost over the 30-year life of other PBR components, the tubing adds \$11.78 to

$515 \$ 18.33 \mathrm{~m}^{-2}$ to the effective cost, bringing the total PBR cost into the range of $\$ 18.26$ to $\$ 28.43 \mathrm{~m}^{-2}$, similar

516 to our estimate of pond costs, all detailed in Table C-1 (SI). It is the large diameter and large volume of 
this PBR design that sets it apart from other tubular and flat plate reactor designs $[21,27,69]$, which by

518 virtue of their much greater surface area:volume ratio are more costly in terms of both area and volume.

519 In the present hybrid system, the total culture volume per hectare is similar for both PBRs and ponds

$520\left(1,344\right.$ and $1,411 \mathrm{~m}^{3} \mathrm{ha}^{-1}$, respectively; Tables 2 and 3), so cost per unit volume is comparable, in the

521 range of $\$ 135$ to $\$ 211$ per $\mathrm{m}^{3}$ for PBRs and $\$ 150$ to $\$ 233$ per $\mathrm{m}^{3}$ for ponds in the Gulf Coast and Hawaii, 522 respectively (Table C-1; SI).

523 Davis et al [7] conclude that PBRs are almost 20 times more costly than open ponds, basing their 524 cost estimate on a small diameter PBR design that accommodates only $200 \mathrm{~m}^{3} \mathrm{ha}^{-1}$, or $<15 \%$ of the 525 culture volume of our PBRs. The order of magnitude difference in cultivation area required to support the 526 same culture volume in such small-diameter PBR systems explains their much greater capital intensity.

527 Similarly, in their 2002 economic analysis, Hallenbeck and Benemann (p 1190) [70] say that "the 528 photobioreactors were not further specified and were merely assumed to cost $\$ 100 / \mathrm{m}^{2}$, which with [other 529 costs] gave a total capital cost of $\$ 135 / \mathrm{m}^{2}$." Acién et al [27] estimated a cost of $€ 165,000$ for a total PBR 530 volume of $33 \mathrm{~m}^{3}$, or $\sim \$ 6,500$ per $\mathrm{m}^{3}$; the high cost of those PBRs is understandable as they are of a very 531 different design, being a vertically suspended array of 9-cm diameter tubes with considerably more 532 permanent infrastructure than required by the design presented here. account for $9 \%$ to $13 \%$ of total capital expenses, about equal to the cost of buildings. Harvesting equipment accounts for $<5 \%$ of capital expenses; electrical and instrumentation equipment costs are similar in magnitude, with all absolute costs greater in Hawaii.

\section{Discussion}

\subsection{High yields compared to other cultivation systems}


the areal yield values for production ponds (Tables 3 and 4) are normalized to the total cultivation area so,

543 for example, the lipid yield of $45 \mathrm{MT} \mathrm{ha}^{-1} \mathrm{yr}^{-1}$ from Desmodesmus production ponds at High N (Table 5A)

544 corresponds to $30 \mathrm{MT} \mathrm{ha}^{-1} \mathrm{yr}^{-1}$ when normalized. To compare with published values of yield from

545 conventional open pond systems we normalize in the same way, as follows. For conventional open pond

546 cultivation systems, pond productivity and yield are also reported with reference to the lit surface area of

547 the production pond, as in Tables 3 and 4. However, those designs typically require inoculation ponds,

548 which must also be included in the total cultivation area. In the representative Lundquist [11] design, only

$5491 \%$ of the cultivation area is dedicated to inoculation and the remaining $99 \%$ to production ponds, but the

550 industry standard described by Benemann et al [4] is 10\%, and "achieving $1 \%$ will require advances in the

551 ability to prevent pond crashes" [12], which has not been demonstrated to date. We therefore assume open

552 pond systems require $10 \%$ of the cultivation area for inoculation, and have normalized reported yields

553 accordingly for the purpose of comparison (Figs 12 and 13).

The yields of algal biomass and lipids achieved in the hybrid cultivation system are greater than reported yields from open ponds at large scale, and greater than many assumed or modeled yields, even after normalizing for the relatively large area dedicated to inoculation in the hybrid system design (Figs 12 and 13). In the High N case, biomass (AFW) and lipid yields are 78 and $30 \mathrm{MT} \mathrm{ha}^{-1} \mathrm{yr}^{-1}$, respectively, for Desmodesmus and 77 and $28 \mathrm{MT} \mathrm{ha}^{-1} \mathrm{yr}^{-1}$, respectively, for Staurosira. The biomass yield of $\sim 75 \mathrm{MT}$

$559 \mathrm{ha}^{-1} \mathrm{yr}^{-1}$ observed for both species is about double that achieved at the Sapphire Energy pilot facility by 560 Liu et al [10], which is among the highest reported based on actual productivity at large scale (Fig 12). The realized lipid yields for Staurosira and Desmodesmus at high N fertilization (Fig 13) are 562 comparable to Chisti's [31] estimated upper limit from conventional open ponds of $\sim 33 \mathrm{MT} \mathrm{ha}^{-1} \mathrm{yr}^{-1}$, and 563 much more than Benemann's [4] estimate of the "best that could be expected is $20,000 \mathrm{~L} \mathrm{ha}^{-1} \mathrm{yr}^{-1}$," or $\sim 18$ $564 \mathrm{MT} \mathrm{ha}^{-1} \mathrm{yr}^{-1}$ algal oil. Flat plate reactors do not seem to do much better. The modeled biomass 565 productivity from Nannochloropsis in flat panel reactors deployed at large scale in Hawaii was $12.8 \mathrm{~g} \mathrm{~m}^{-2}$ 
$\mathrm{d}^{-1}[21]$, or $47 \mathrm{MT} \mathrm{ha}^{-1} \mathrm{yr}^{-1}$, with a corresponding lipid yield of $20 \mathrm{MT} \mathrm{ha}^{-1} \mathrm{yr}^{-1}$, equal to yields observed

567 in the Low N case for Staurosira and Desmodesmus.

568 We offer several reasons why the lipid yields from open ponds reported here equal or exceed the

569 perceived upper limit for conventional open pond systems [6, 31], and exceed all reports we could find of

570 sustained biomass yields from open ponds at a scale $>10 \mathrm{~m}^{2}$. First, we attribute much to the process of

571 strain selection, which clearly identified Staurosira and Desmosdesmus as leaders among 500 candidates;

572 both strains had $>36 \%$ lipid content at large-scale, even with high $\mathrm{N}$ fertilization. Many published

573 measurements of large-scale production are based on the cultivation of either unspecified strains or strains

574 that were not selected for lipid production.

Second, we conclude that adding nitrogen is a good thing to do; results clearly show that by $\mathrm{MT} \mathrm{ha}^{-1} \mathrm{yr}^{-1}$ for both species, but the total lipid yield also increases, by about 50\%, to $28 \mathrm{MT} \mathrm{ha}^{-1} \mathrm{yr}^{-1}$ for

578 Staurosira and $30 \mathrm{MT} \mathrm{ha}^{-1} \mathrm{yr}^{-1}$ for Desmodesmus. This result is entirely opposite to the projection of 579 Lardon et al [9] that an increase in nitrogen would reduce lipid yields of Chlorella from $27 \mathrm{MT} \mathrm{ha}^{-1} \mathrm{yr}^{-1}$ to

$58016 \mathrm{MT} \mathrm{ha}^{-1} \mathrm{yr}^{-1}$, and that of Vasuvedan et al [15], who expect that lipid yield would be reduced from 63

$581 \mathrm{MT} \mathrm{ha}^{-1} \mathrm{yr}^{-1}$ to $16 \mathrm{MT} \mathrm{ha}^{-1} \mathrm{yr}^{-1}$ (Fig 13). Furthermore, we have demonstrated how one may employ the 582 Fertilizer Ratio to obtain the highest biomass yield possible while ensuring zero discharge of dissolved 583 nitrogen.

Third, we suggest that pond depth may be a factor in limiting yields. From a preliminary study of 585 Staurosira production in $400 \mathrm{~m}^{2}$ open ponds operated side-by-side at 15, 20, and $30 \mathrm{~cm}$ depths, we found 586 that deeper pond cultures became light-limited sooner, and observed that 15-cm deep ponds gave the 587 highest yields. It may not be purely coincidental that observed yields lower than ours were produced in 30 to 35-cm deep ponds (Table 10). Weissman et al [71] estimated relatively high average biomass productivity values of $16 \mathrm{~g} \mathrm{~m}^{-2} \mathrm{~d}^{-1}$, or $58 \mathrm{MT} \mathrm{ha}^{-1} \mathrm{yr}^{-1}$, from fall and winter experiments in $1 \mathrm{~m}^{2}, 15-\mathrm{cm}$ 
deep ponds using strains selected for high growth and lipid characteristics, but rates at larger pond scales of $3 \mathrm{~m}^{2}$ or $1,000 \mathrm{~m}^{2}$ were substantially lower. open ponds. Conventional open ponds are typically operated as semi-continuous cultures, partially

594 harvested and refilled daily at rates ranging from $10 \% \mathrm{~d}^{-1}[12]$ to an average of $25 \% \mathrm{~d}^{-1}[4,11]$ until some 595 part of the system crashes, at which time it is restarted from inoculum ponds. Open ponds in the hybrid 596 system, by contrast, are harvested and re-inoculated either daily or, for production ponds, every other day, 597 while the inoculum (PBR) system is harvested at a rate of $50 \% \mathrm{~d}^{-1}$. Simply considering these two systems 598 at facility scale as two semi-continuous culture systems, the conventional open pond system operated at a 599 dilution rate of $25 \% \mathrm{~d}^{-1}$ should, on average, yield less biomass than a hybrid system diluted at almost 600 twice the rate. Viewed from this perspective, it is perhaps not surprising that a conventional pond 601 harvested at $10 \% \mathrm{~d}^{-1}$ yields only $11 \mathrm{MT} \mathrm{ha}^{-1} \mathrm{yr}^{-1}$ of Nannochloropsis biomass [12].

\subsection{Achieving higher yields}

603 We suggest three specific areas where improved processes would lead to substantially greater

604 yields. First, new fertilizers (nutrient medium) should be developed. Fertilizer development is the 605 fundamental basis of improved yields in global agriculture over the past 50 years [72], but algae 606 production still relies on nutrient media developed 50 years ago [41]. As one small example of what 607 might be accomplished, we find the source of $\mathrm{N}$ may significantly improve yield. In high throughput 608 screening we compared the doubling rate of 24 lead candidate strains on $\mathrm{NH}_{4} \mathrm{vs} \mathrm{NO}_{3}$, and found that, on 609 average, doubling rates were $20 \%$ greater on $\mathrm{NH}_{4}$. We used $\mathrm{NO}_{3}$ for large-scale production at KDF.

610 However, were $\mathrm{NH}_{4}$ to be used we would expect $\mathrm{N}$ uptake rates to be $20 \%$ greater, leading to yields of 94

$611 \mathrm{MT} \mathrm{ha}^{-1} \mathrm{yr}^{-1}$ biomass and $38 \mathrm{MT} \mathrm{ha}^{-1} \mathrm{yr}^{-1}$ lipid. We believe that serious research in algae nutrient media, 612 having been ignored for half a century, would lead to rapid advances in demonstrated yield.

613 Second, methods should be explored to reduce respiratory losses of C. We estimate average 614 nighttime respiratory losses of $12 \%$, which amounts to a comparable loss in yield from production ponds; 615 for High N Desmodesmus ponds this equates to a loss of $25 \mathrm{MT} \mathrm{ha}^{-1} \mathrm{yr}^{-1}$, so innovations in reducing 
nighttime respiration would improve yield accordingly. It is worth noting that nighttime respiratory losses

617 are compounded so conventional open pond production systems, which typically have longer residence

618 times $[4,11]$, are inherently less efficient in net $\mathrm{C}$ sequestration.

619 Third, the management of gas exchange in general should have a beneficial effect on yield.

620 Oxygen concentrations often exceeded $400 \%$ saturation in our pond cultures, well beyond levels known

621 to inhibit photosynthesis [50,73], were generally reached before noon, and lasted for several hours [65].

622 It is difficult to accurately estimate how much yields could be increased by reducing $\mathrm{O}_{2}$ concentrations to

$623<150 \%$, but we believe the effect could be significant. This would require a method of enhancing the rates

624 of gas exchange during the middle of the day, enabling an enhanced uptake rate of $\mathrm{CO}_{2}$ and manifested

625 directly as increased productivity. Such gains as might be achieved through the ability to manipulate gas

626 exchange rates could be, we believe, in the range of 10 to $20 \mathrm{MT}_{\mathrm{ha}}{ }^{-1} \mathrm{yr}^{-1}$ or more. In summary, we

627 believe it remains realistic to pursue production targets of $100 \mathrm{MT} \mathrm{ha}^{-1} \mathrm{yr}^{-1}$ biomass and 45 to $50 \mathrm{MT}^{-1}$

$628 \mathrm{yr}^{-1}$ algal oil.

\subsection{Achieving lower costs}

The PBR design presented here is demonstrably effective at an order of magnitude less cost, per

631 ha or per $\mathrm{m}^{3}$, than other common designs [19, 20, 27], with installed costs comparable to those for 632 conventional open ponds [11]. This finding suggests that PBRs warrant reconsideration in the design of 633 large-scale production facilities. Further cost reductions are explored in detail by Beal et al [1], who 634 consider a range of unit operations that lead to demonstrable improvements in the entire production 635 process. tremendous potential of algal biofuels. Our facility model assumes a nearby, nearly pure $\mathrm{CO}_{2}$ source,

638 located within $15 \mathrm{~km}$. However, in the real world pure $\mathrm{CO}_{2}$ sources are rare, and even dilute sources may 639 not be near large tracts of land. The facility cost increases at the rate of $\sim \$ 1,300 \mathrm{ha}^{-1}$ for each $\mathrm{km}$ of $\mathrm{CO}_{2}$ 640 pipeline, so at a distance of $100 \mathrm{~km}$ the cost of the $\mathrm{CO}_{2}$ delivery system would be substantial. Unless 641 other methods of $\mathrm{CO}_{2}$ capture and utilization are developed and deployed, the algae biofuels industry will 
642 forever be limited by its short tether to stack gases. If yields can be pushed significantly beyond what we

643 have demonstrated here, $75 \mathrm{MT} \mathrm{ha}^{-1} \mathrm{yr}^{-1}$ biomass and $30 \mathrm{MT} \mathrm{ha}^{-1} \mathrm{yr}^{-1}$, or 35,000 $\mathrm{L} \mathrm{ha}^{-1} \mathrm{yr}^{-1}$ algal oil, then

644 other sources of $\mathrm{CO}_{2}$ may well be worth pursuing because the low-hanging fruit of nearby, nearly pure

$645 \mathrm{CO}_{2}$ sources will quickly be claimed, leaving no alternative. 


\section{Acknowledgments}

For their collaboration in developing and managing the research plan executed here we thank our colleagues Robert Bidigare, John Cullen, Earl Fusato, C. Barry Raleigh, and Donald Redalje, and in particular William Cochlan, who directly managed all outdoor cultivation and harvesting at Cellana for much of the period reported here.

For the quality and sheer magnitude and quality of results they produced over a 1.5 -year period at Cellana, we thank Joseph Alapai, Xuemei Bai, Liza Barney, Melissa Bentley, Beth Bernhardt, Julia Betts, Bill Bjornson, Pam Chia, Andrea Danihel, Eric DelaRosa, Ryan Dorland, Thomas Erlenbeck, Lauren Farrar, Sheri Floge, Hugh Forehead, Gabe Foreman, Rhea Foreman, Nikki Goes, Lynn Griswold, Richard Henderson, Julian Herndon, Cassy Hertz, Chris Ikeda, Jessica Johnson, Ben Kama, Byron Kay, Emily Knurek, Avery Kramer, Clinton Leleiwi, Russell Leleiwi, Jason Loa, Mai Lopez, Gary Maillet, Matt McGivern, Ashley Morrow, Paul Neilson, Jeff Obbard, Shon Olivera, Dünya Önen, George Paleudis, Blair Paul, Lisa Pickell, Justin Pihi, Peter Prentiss, Regina Radan, Mariana Rangelova, Erin Rietow, Egan Rowe, Becky Schilling, Chris Scharnus, Michael Schvarcz, Thomas Stone, Skye Thomas-Hall, Thieny Trinh, George Vozhdayev, Michael Workman, Keau Yuen and Mark Yuen.

At Royal Dutch Shell, for the vision to fund this project from 2007 to 2011 we thank Graeme Sweeney and Rob Routs, for actually ensuring that funding we thank Wolbert Allart and Bill Weil, and for the courage to lead the project we thank Gabriel DeScheemaker, all of whom stepped outside their normal comfort zones. Just as Cellana's Kona demonstration facility was being completed in 2010 the funding for this project was augmented by an award from the US Department of Energy (DEEE0003371), which ultimately made this publication possible. The funding sponsors for this project had no role in determining the study design, the collection, analysis, or interpretation of data, nor the writing of this article, nor the decision to submit the article for publication.

We thank Valerie Harmon, Avery Kramer, Martin Sabarsky, Jefferson Tester and two anonymous reviewers for their critical contributions to the manuscript. 
648 1. Beal, C.M., et al., Algal biofuel production for fuels and feed in a 100-ha facility: a comprehensive techno-economic analysis and life-cycle assessment. Algal Research, 2014: p. In review.

651 2. Amer, L., B. Adhikari, and J. Pellegrino, Technoeconomic analysis of five microalgae-to-biofuels processes of varying complexity. Bioresource Technology, 2011. 102(20): p. 9350-9359.

3. Azadi, P., et al., The carbon footprint and non-renewable energy demand of algae-derived biodiesel. Applied Energy, 2014. 113(0): p. 1632-1644.

4. Benemann, J., I. Woertz, and T. Lundquist, Life Cycle Assessment for Microalgae Oil Production. Disruptive Science and Technology, 2012. 1(2): p. 68-78.

5. Benemann, J.R. and W.J. Oswald, Systems and economic analysis of microalgae ponds for

6. Brune, D.E., T.J. Lundquist, and J.R. Benemann, Microalgal Biomass for Greenhouse Gas Reductions: Potential for Replacement of Fossil Fuels and Animal Feeds. Journal of

7. Davis, R., A. Aden, and P.T. Pienkos, Techno-economic analysis of autotrophic microalgae for 664 fuel production. Applied Energy, 2011. 88(10): p. 3524-3531. results and comparisons. Bioresour Technol, 2011. 102(10): p. 5800-7. 
672 11. Lundquist, T., et al., A realistic technology and engineering assessment of algal biofuel

673

674

675

676

677

678

679

680

681

682

683

684

685

686

687

688

689

690

691

692

693

694

695

production. 2010, Energy Biosciences Institute, University of California: Berkeley, California. p. 178.

12. Passell, H., et al., Algae biodiesel life cycle assessment using current commercial data. J Environ Manage, 2013. 129: p. 103-11.

13. Shirvani, T., et al., Life cycle energy and greenhouse gas analysis for algae-derived biodiesel. Energy \& Environmental Science, 2011. 4(10): p. 3773.

14. Stephenson, A.L., et al., Life-Cycle Assessment of Potential Algal Biodiesel Production in the United Kingdom: A Comparison of Raceways and Air-Lift Tubular Bioreactors. Energy \& Fuels, 2010. 24(7): p. 4062-4077.

15. Vasudevan, V., et al., Environmental performance of algal biofuel technology options. Environ Sci Technol, 2012. 46(4): p. 2451-9.

16. Ventura, J.R., et al., Life cycle analyses of $\mathrm{CO}_{2}$, energy, and cost for four different routes of microalgal bioenergy conversion. Bioresour Technol, 2013. 137: p. 302-10.

17. Zaimes, G.G. and V. Khanna, Microalgal biomass production pathways: evaluation of life cycle environmental impacts. Biotechnol Biofuels, 2013. 6(1): p. 88.

18. Batan, L., et al., Net Energy and Greenhouse Gas Emission Evaluation of Biodiesel Derived from Microalgae. Environmental Science \& Technology, 2010. 44(20): p. 7975-7980.

19. Davis, R.E., et al., Integrated evaluation of cost, emissions, and resource potential for algal biofuels at the national scale. Environ Sci Technol, 2014. 48(10): p. 6035-42.

20. Jonker, J.G.G. and A.P.C. Faaij, Techno-economic assessment of micro-algae as feedstock for renewable bio-energy production. Applied Energy, 2013. 102: p. 461-475.

21. Moody, J.W., C.M. McGinty, and J.C. Quinn, Global evaluation of biofuel potential from microalgae. Proceedings of the National Academy of Sciences, 2014. 
696 22. Resurreccion, E.P., et al., Comparison of algae cultivation methods for bioenergy production using a combined life cycle assessment and life cycle costing approach. Bioresour Technol, 2012. 126: p. 298-306.

699 23. Slegers, P.M., et al., Scenario evaluation of open pond microalgae production. Algal Research, 2013. 2(4): p. 358-368.

701 24. Craggs, R., D. Sutherland, and H. Campbell, Hectare-scale demonstration of high rate algal 702 ponds for enhanced wastewater treatment and biofuel production. Journal of Applied Phycology, $703 \quad 2012.24(3):$ p. 329-337.

$70425 . \quad$ Jimenez, C., Relationship between physicochemical variables and productivity in open ponds for 705 the production of Spirulina: a predictive model of algal yield. Aquaculture, 2003. 221(1-4): p. 331-345.

26. Park, J.B., R.J. Craggs, and A.N. Shilton, Enhancing biomass energy yield from pilot-scale high rate algal ponds with recycling. Water Res, 2013. 47(13): p. 4422-32.

709

27. Acien-Fernandez, F.G., et al., Production cost of a real microalgae production plant and strategies to reduce it. Biotechnol Adv, 2012. 30(6): p. 1344-53.

711 28. Molina Grima, E., et al., Recovery of microalgal biomass and metabolites: process options and economics. Biotechnol Adv, 2003. 20: p. 491-515.

713 29. Huntley, M.E. and D.G. Redalje, $\mathrm{CO}_{2}$ mitigation and renewable oil from photosynthetic microbes: a new appraisal. Mitigation and Adaptation Strategies for Global Change, 2007. 12(4):

30. Rodolfi, L., et al., Microalgae for oil: strain selection, induction of lipid synthesis and outdoor mass cultivation in a low-cost photobioreactor. Biotechnol Bioeng, 2009. 102(1): p. 100-12. 36(1): p. 158-162. 
721 33. Richardson, J.W., M.D. Johnson, and J.L. Outlaw, Economic comparison of open pond raceways to photo bio-reactors for profitable production of algae for transportation fuels in the Southwest.

724 34. Wood, A.M., R.C. Everroad, and L.M. Wingard, Measuring growth rates in microalgal cultures, 725

37. Ringuet, S., L. Sassano, and Z.I. Johnson, A suite of microplate reader-based colorimetric

38. Wiebe, P.H., S. Boyd, and J.L. Cox, Relationships between zooplankton displacement volume,

39. Gardner, W.S., et al., Micromethod for lipids in aquatic invertebrates. Limnology and

40. Silversand, C. and C. Haux, Improved high-performance liquid chromatographic method for the

41. Andersen, R.A., et al., Appendix A - Recipes for freshwater and seawater media, in Algal separation and quantification of lipid classes: Application to fish lipids. . Journal of Chromatography B, 1997. 703: p. 7-14. Culturing Techniques, R.A. Andersen, Editor. 2005, Elsevier. Amsterdam. p. 429-532.

42. Carvalho, A.P., L.A. Meireles, and F.X. Malcata, Microalgal reactors: A review of enclosed system designs and performances. Biotechnology Progress, 2006. 22(6): p. 1490-1506.

43. Olaizola, M., Commercial production of astaxanthin from Haematococcus pluvialis using 25,000-liter outdoor photobioreactors. Journal of Applied Phycology, 2000. 12(3-5): p. 499-506. 
44. Molina, E., et al., Tubular photobioreactor design for algal cultures. Journal of Biotechnology, 2001. 92(2): p. 113-131.

45. Ugwu, C.U., H. Aoyagi, and H. Uchiyama, Photobioreactors for mass cultivation of algae. Bioresource Technology, 2008. 99(10): p. 4021-4028.

46. Lee, E., et al., Design tool and guidelines for outdoor photobioreactors. Chemical Engineering Science, 2014. 106: p. 18-29.

47. Pulz, O., Photobioreactors: production systems for phototrophic microorganisms. Applied Microbiology and Biotechnology, 2001. 57(3): p. 287-293.

48. Gerhart, P.M., R.J. Gross, and J.I. Hochstein, Fundamentals of Fluid Mechanics. 2nd Edition ed. 1992, Boston: Addison-Wesley

49. Moheimani, N.R. and M.A. Borowitzka, Limits to productivity of the alga Pleurochrysis carterae (Haptophyta) grown in outdoor raceway ponds. Biotechnol Bioeng, 2007. 96(1): p. 27-36.

50. Peng, L., C.Q. Lan, and Z. Zhang, Evolution, detrimental effects, and removal of oxygen in microalga cultures: A review. Environmental Progress \& Sustainable Energy, 2013. 32(4): p. 982-988.

51. Mendoza, J.L., et al., Fluid-dynamic characterization of real-scale raceway reactors for microalgae production. Biomass and Bioenergy, 2013. 54: p. 267-275.

52. Monteith, J.L., Evaporation and environment. Symp Soc Exp Biol, 1965. 19: p. 205-34.

53. Johnson, Z.I., Pond evaporation. 2010, Marine Algae Consortium Technical Report. p. 1-18.

54. Borowitzka, M.A., ed. Culturing microalgae in outdoor ponds. ed. R.A. Andersen. 2005, Elsevier: Amsterdam. 205-218.

55. Weissman, J.C. and R.P. Goebel, Design and analysis of microalgal open pond systems for the purpose of producing fuels. 1987, Solar Energy Research Institute: Golden, Colorado. p. 1-231.

56. Chiaramonti, D., et al., Review of energy balance in raceway ponds for microalgae cultivation: Re-thinking a traditional system is possible. Applied Energy, 2013. 102: p. 101-111. 
57. Sarthou, G., et al., Growth physiology and fate of diatoms in the ocean: a review. Journal of Sea Research, 2005. 53(1-2): p. 25-42.

58. Passow, U., Species-specific sedimentation and sinking rates in diatoms. Marine Biology, 1991. 108(3): p. 449-455.

59. Smayda, T.J., Normal and accelerated sinking of phytoplankton in the sea. Marine Geology, 1971. 11(2): p. 105-122.

60. Geider, R.J. and J. La Roche, Redfield revisited: variability of $C: N$ : P in marine microalgae and its biochemical basis. European Journal of Phycology, 2002. 37(1): p. 1-17.

61. Johnson, Z.I., Evaluation of pond liner materials - effects on algal cultures. 2010, Marine Algae Consortium Technical Report. p. 1-2?

62. Ketheesan, B. and N. Nirmalakhandan, Development of a new airlift-driven raceway reactor for algal cultivation. Applied Energy, 2011. 88(10): p. 3370-3376.

63. Knuckey, R.M., et al., Production of microalgal concentrates by flocculation and their assessment as aquaculture feeds. Aquacultural Engineering, 2006. 35(3): p. 300-313.

64. Jameson, G.J., Hydrophobicity and floc density in induced-air flotation for water treatment. Colloids and Surfaces a-Physicochemical and Engineering Aspects, 1999. 151(1-2): p. 269-281.

65. Ferron, S., et al., Air-Water Fluxes of $\mathrm{N}_{2} \mathrm{O}$ and $\mathrm{CH}_{4}$ during Microalgae (Staurosira sp.) Cultivation in an Open Raceway Pond. Environmental Science \& Technology, 2012. 46(19): p. 10842-10848.

66. Fagerstone, K.D., et al., Quantitative measurement of direct nitrous oxide emissions from microalgae cultivation. Environ Sci Technol, 2011. 45(21): p. 9449-56.

67. Hardy, R.W., Utilization of plant proteins in fish diets: effects of global demand and supplies of fishmeal. Aquaculture Research, 2010. 41(5): p. 770-776.

68. RS Means Online - Complete Library. 2014, http://www.rsmeansonline.com/. 
795 69. Brennan, L. and P. Owende, Biofuels from microalgae-A review of technologies for production, 796 processing, and extractions of biofuels and co-products. Renewable and Sustainable Energy $797 \quad$ Reviews, 2010. 14(2): p. 557-577.

798 70. Hallenbeck, P.C. and J.R. Benemann, Biological hydrogen production; fundamentals and limiting 799 processes. International Journal of Hydrogen Energy, 2002. 27: p. 1185-1193.

800 71. Weissman, J.C., D.M. Tillet, and R.P. Goebel, Design and operation of an outdoor microalgae 801 test facility; Final subcontract report. 1989, Solar Energy Research Institute: Golden, Colorado. 802 p. $1-68$.

803 72. Godfray, H.C.J., et al., Food Security: The Challenge of Feeding 9 Billion People. Science, 2010. $804 \quad$ 327(5967): p. 812-818.

805 73. Mendoza, J.L., et al., Oxygen transfer and evolution in microalgal culture in open raceways. 806 Bioresour Technol, 2013. 137: p. 188-95.

807 


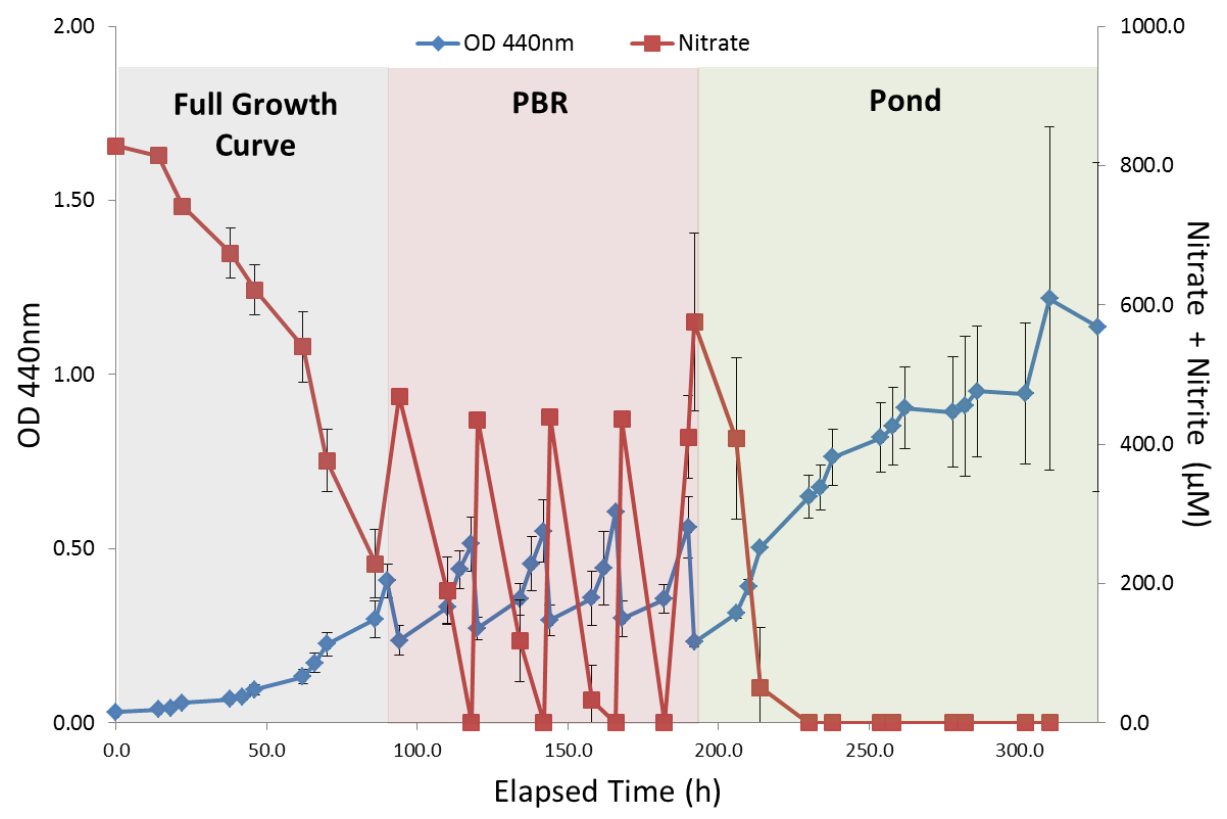

Figure 1 Mid-scale screening trial results for Staurosira sp., showing changes in total dissolved N ( $\square$ ) and biomass $(\diamond)$, measured as optical density at $440 \mathrm{~nm}$. Error bars are standard deviation for 3 replicate reactors. 

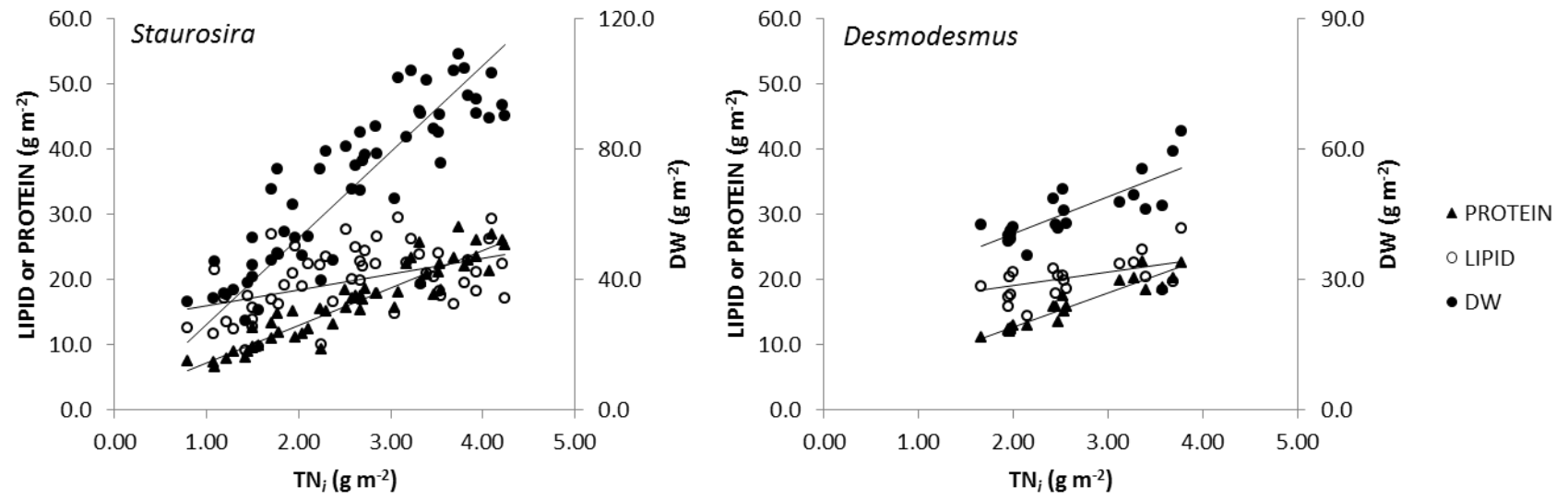

Figure 2 Yield of lipid, protein, and dry weight from 2-day pond cultures as a function of initial total nitrogen $\left(\mathrm{TN}_{i}\right)$, all in $\mathrm{g} \mathrm{m}^{-2}$ 

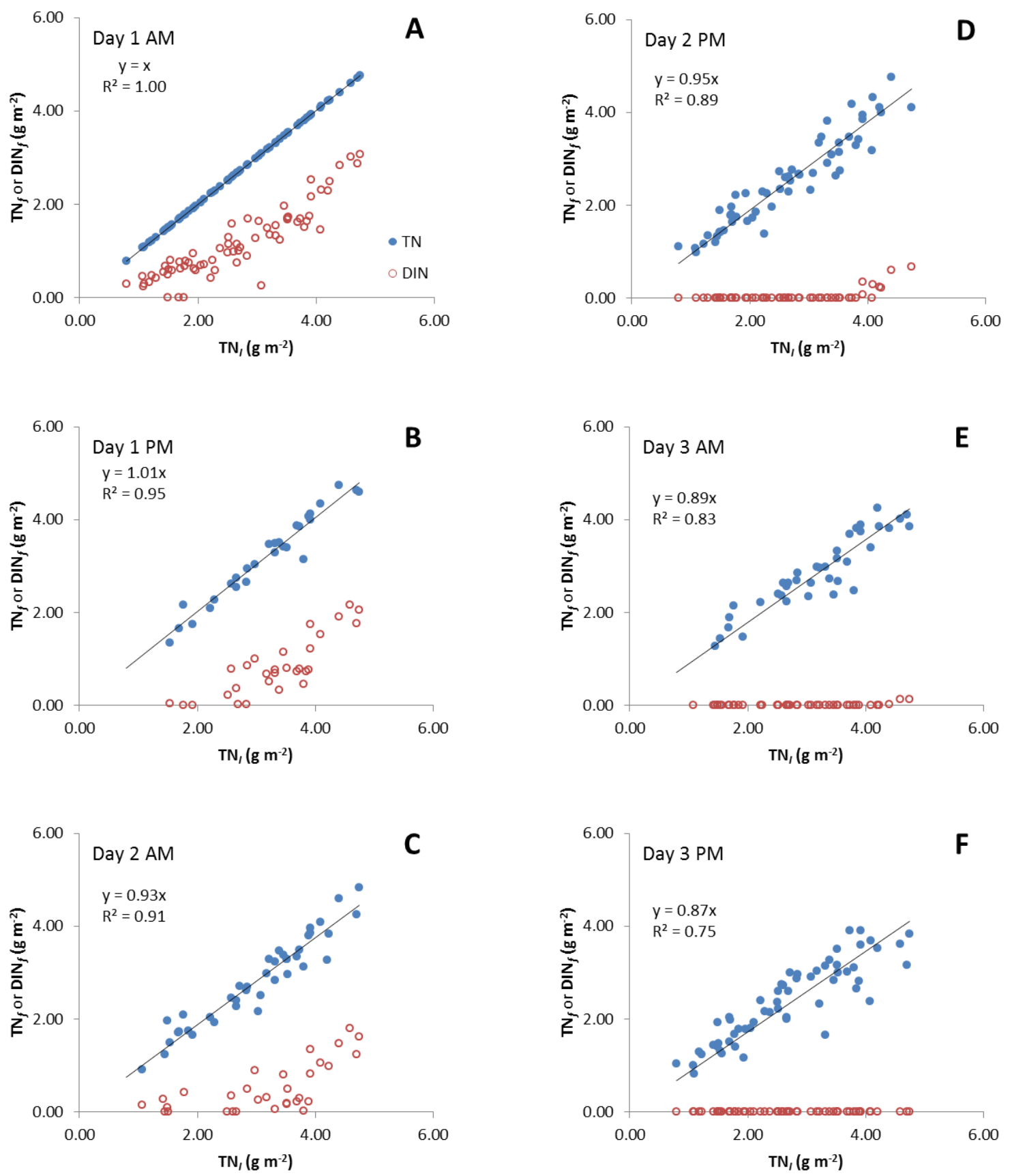

Figure 3: Staurosira sp: Time series of $\operatorname{DIN}_{f}\left(\bigcirc\right.$; final dissolved inorganic nitrogen) and $\mathrm{TN}_{f}(\bullet$; final total nitrogen) as a function of initial total nitrogen $\left(\mathrm{TN}_{i}\right)$, in 3-day pond batch cultures. After inoculation before sunrise on Day 1, ponds were sampled near sunrise (AM: 06:00 to 08:00 LT) and sunset (PM: 16:00 to 18:00 LT) on the days indicated. 

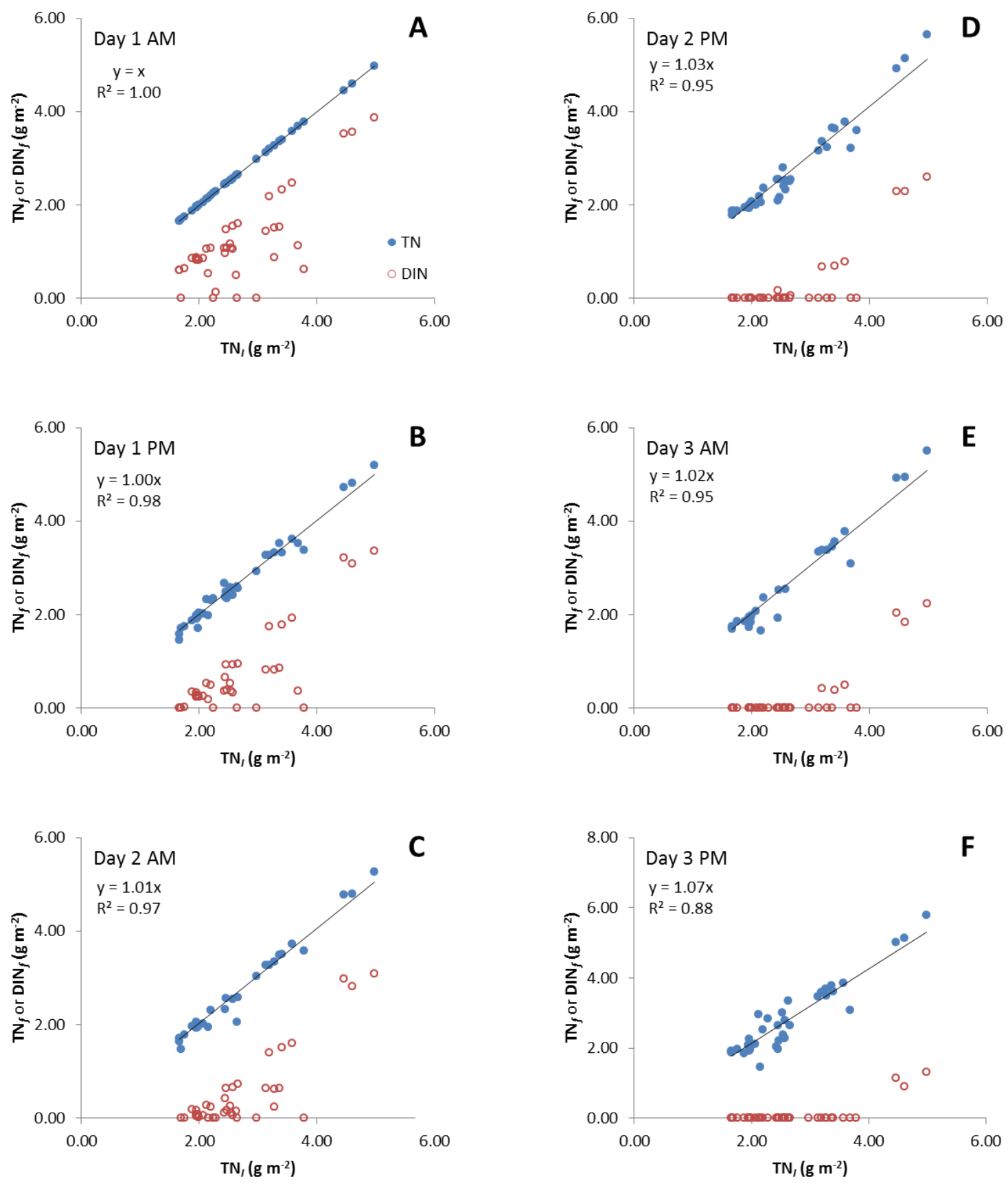

Figure 4: Desmodesmus sp: Time series of $\operatorname{DIN}_{f}\left(\bigcirc\right.$; final dissolved inorganic nitrogen) and $\mathrm{TN}_{f}(\bullet$; final total nitrogen) as a function of initial total nitrogen $\left(\mathrm{TN}_{i}\right)$, in 3-day pond batch cultures. After inoculation before sunrise on Day 1, ponds were sampled near sunrise (AM: 06:00 to 08:00 LT) and sunset (PM: 16:00 to 18:00 LT) on the days indicated. 


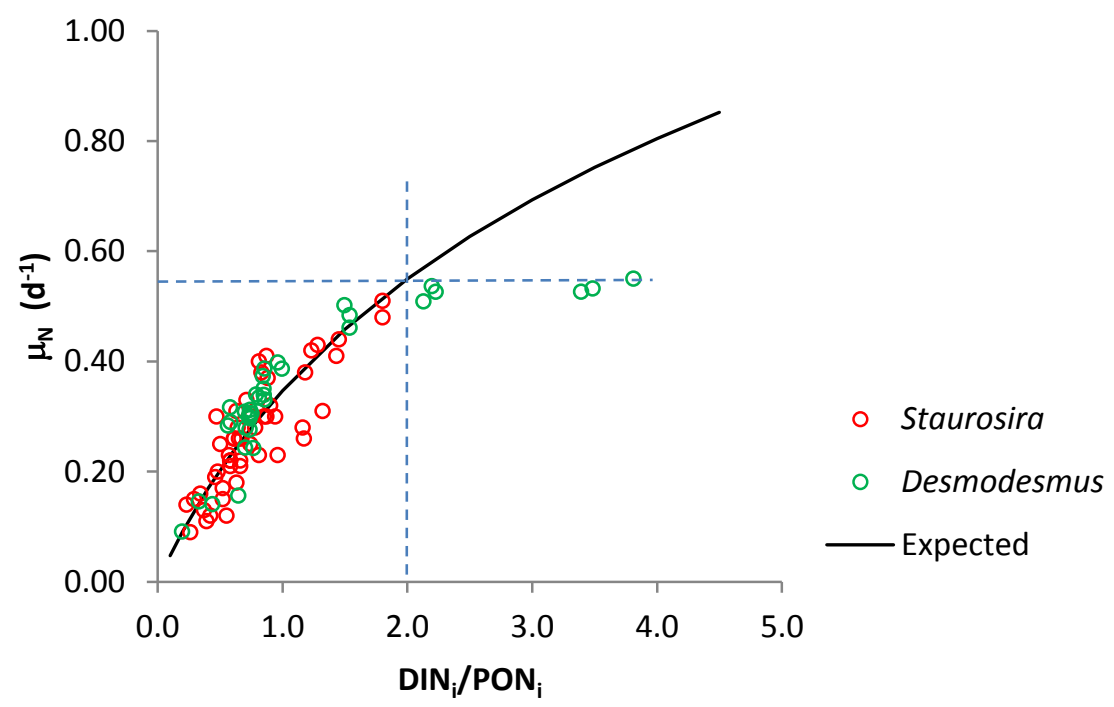

Figure 5: Doubling rate of PON, $\mu_{N}\left(\mathrm{~d}^{-1}\right)$, as a function of the fertilizer ratio, $\mathrm{DIN}_{\mathrm{i}} / \mathrm{PON}_{\mathrm{i}}$, on Day 2 for Staurosira (O) and Desmodesmus ( $\mathrm{O}$ ), compared to the expected doubling rate if all DIN is converted to PON, based on equation (3). The dashed lines indicate values used for the Base Case 

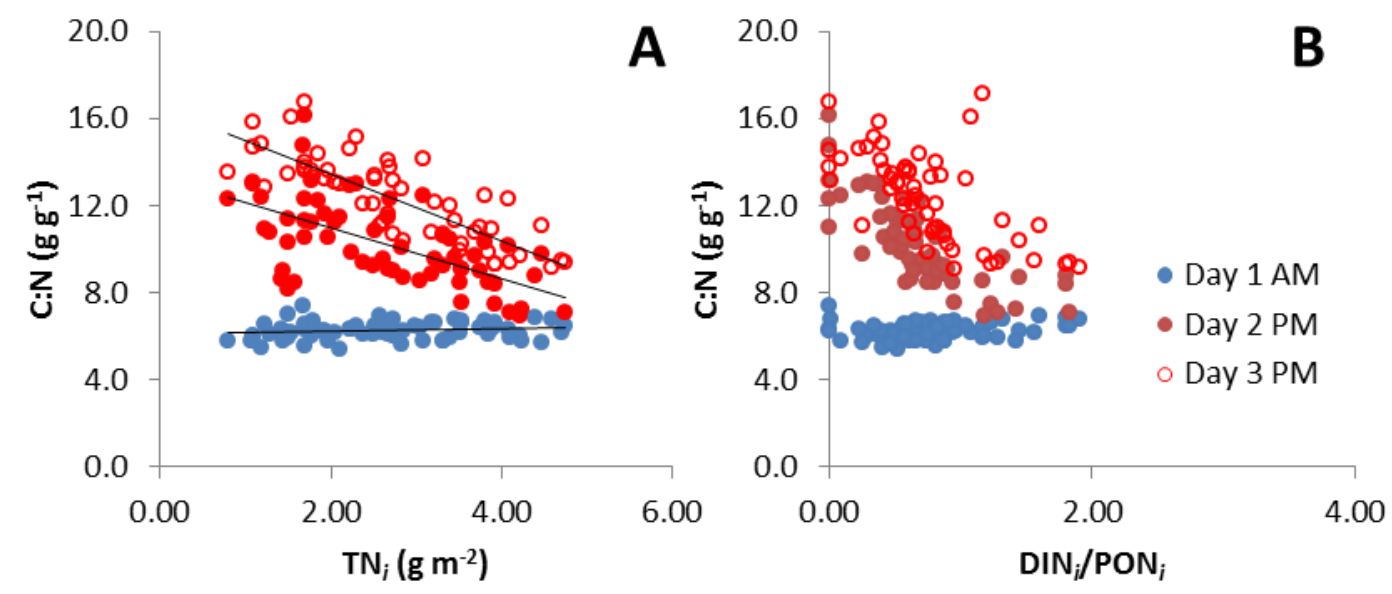

Figure 6: Staurosira sp. C:N ratio as a function of (A) initial total nitrogen $\left(\mathrm{TN}_{i}\right)$ and $(\mathrm{B})$ the Fertilizer Ratio on Day 1 AM (•), Day 2 PM (•), and Day 3 PM (०). 

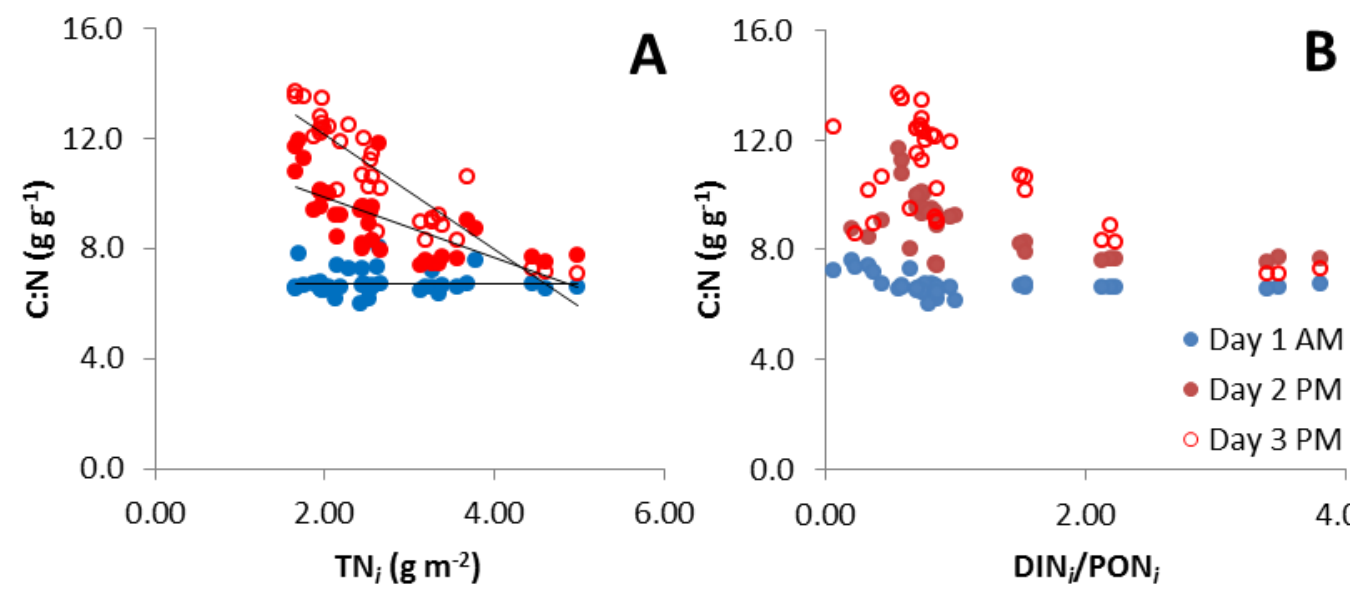

Figure 7: Desmodesmus sp: C:N ratio as a function of (A) initial total nitrogen $\left(\mathrm{TN}_{i}\right)$ and $(\mathrm{B})$ the Fertilizer Ratio on Day 1 AM (•), Day 2 PM (•), and Day 3 PM (०). 

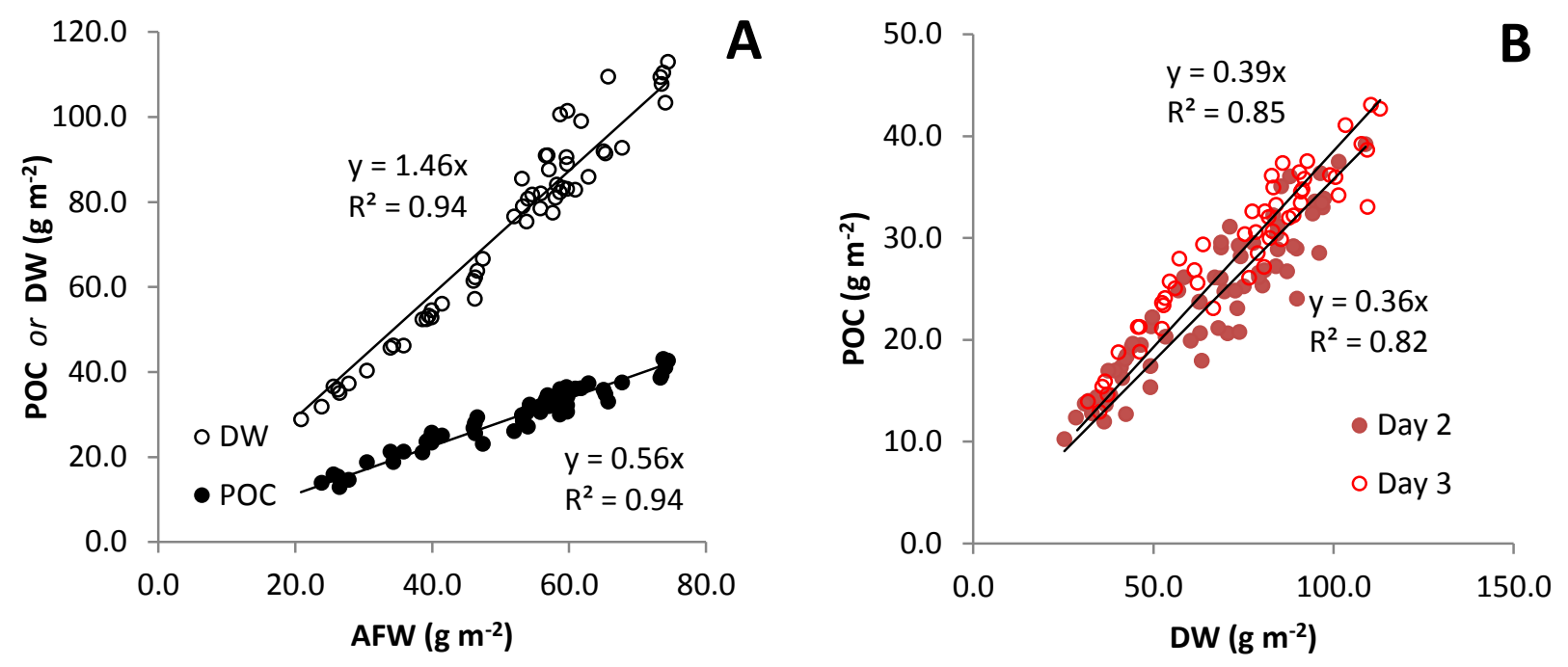

Figure 8: Staurosira sp: (A) Particulate organic carbon (•) and dry weight (O) as a function of ash-free dry weight at harvest time on Day 3. (B) POC as a function of dry weight at harvest time on Day 2 (•) and Day $3(0)$. 

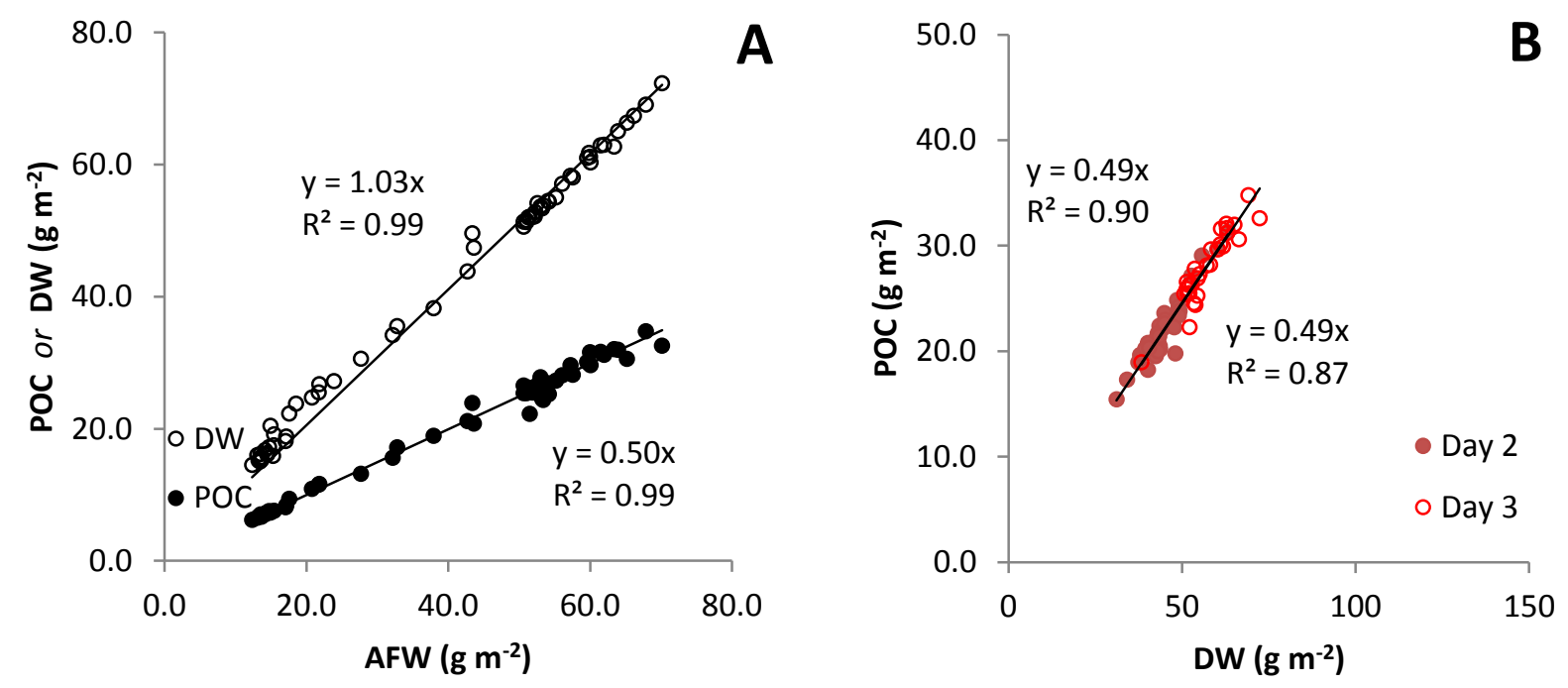

10.0

10.0

B

50

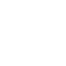

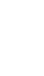

200.0 

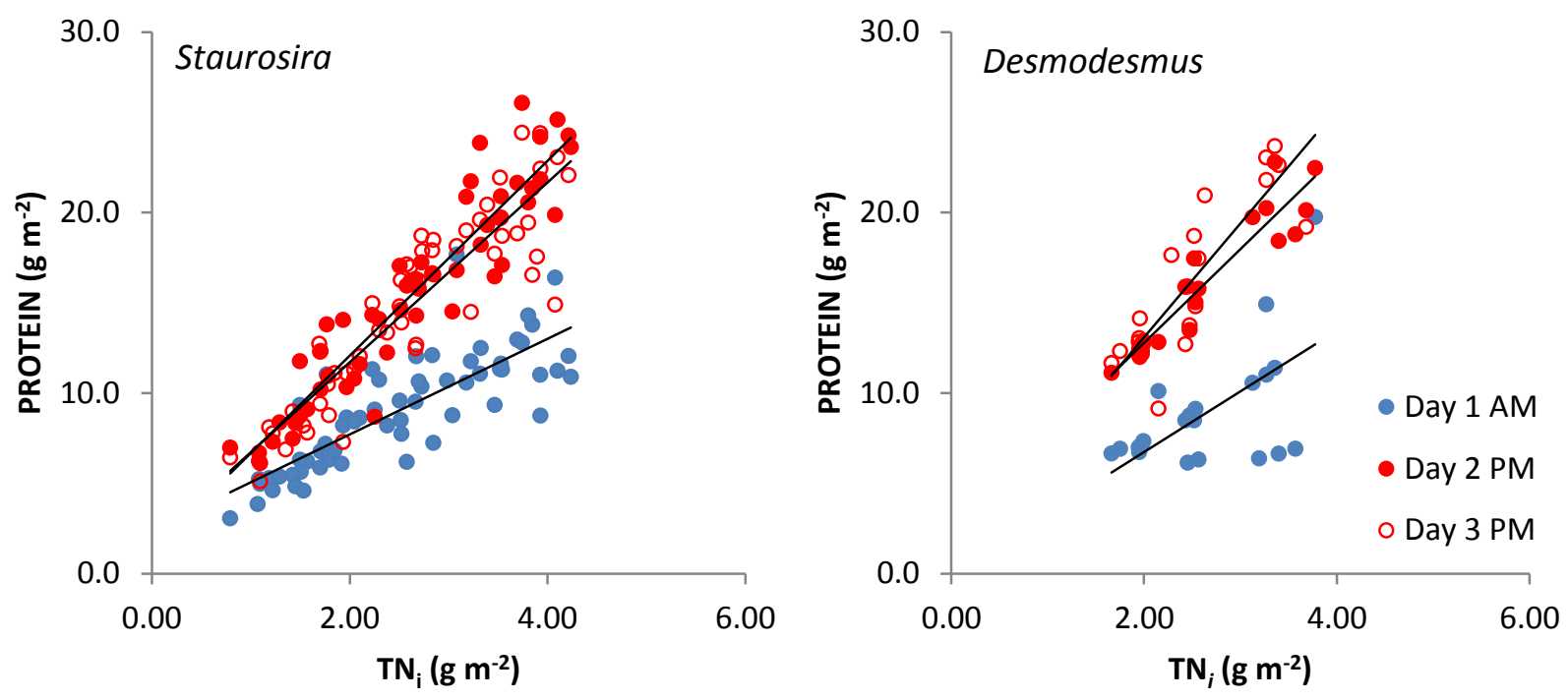

Figure 11: Protein yield as a function of total initial nitrogen $\left(\mathrm{TN}_{i}\right)$ for both species at the time of inoculation on Day $1(\bullet)$ and at harvest time on Day $2(\bullet)$ and Day $3(0)$. 


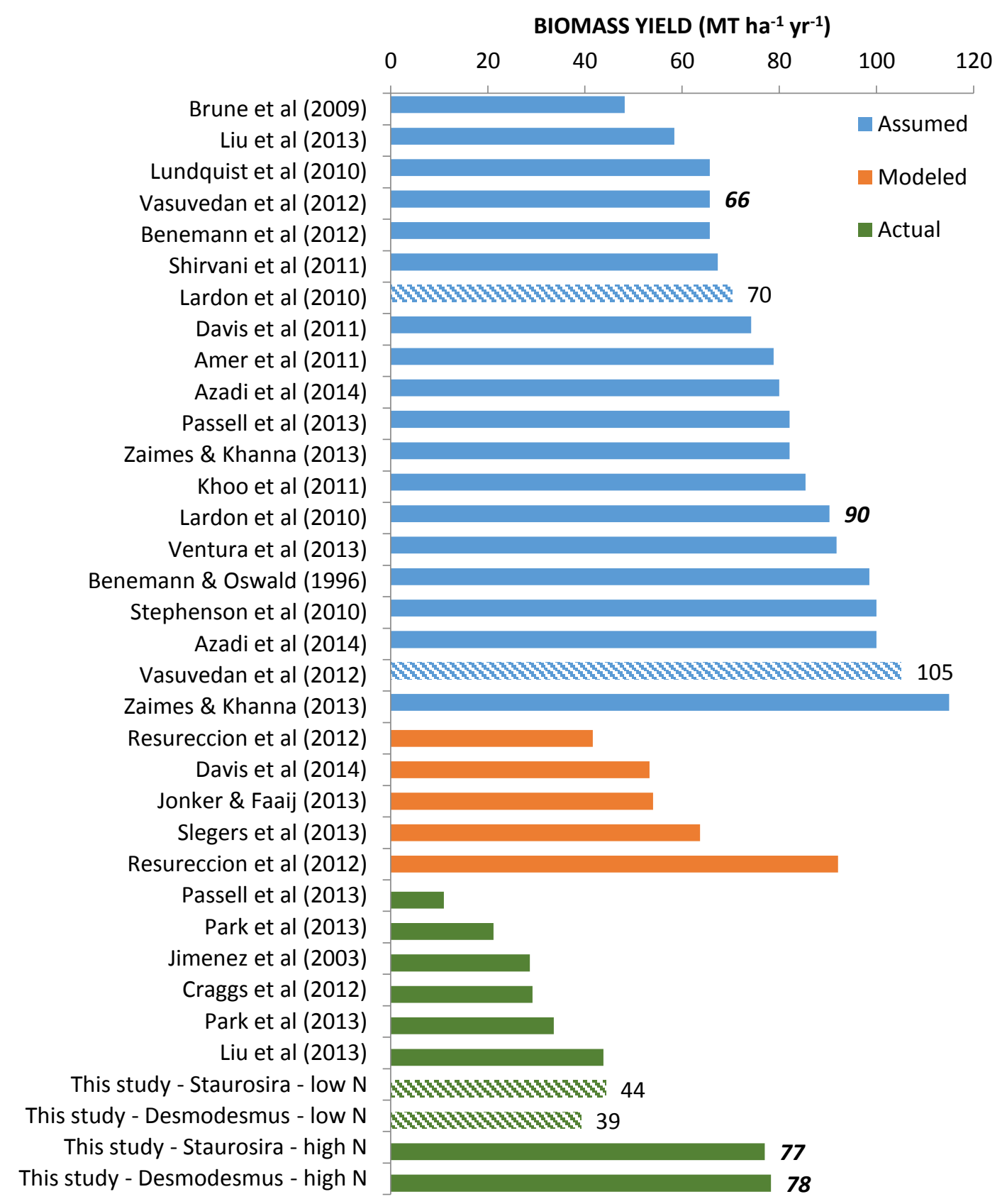

Figure 12 Reported annual yields of biomass (MT ha- $\left.\mathrm{yr}^{-1}\right)$ in techno-economic and/or life cycle assessment studies of three types: using (a) assumed, (b) modeled, and (c) realized values of productivity, for pond systems $>10 \mathrm{~m}^{2}$, compared to values reported here for Staurosira and Desmodesmus. Low $\mathrm{N}$ treatments: hatched bars, data labels in italics. High $\mathrm{N}$ treatments: solid bars, data labels in bold italics. References: [2-17, 20, 22-26]. 


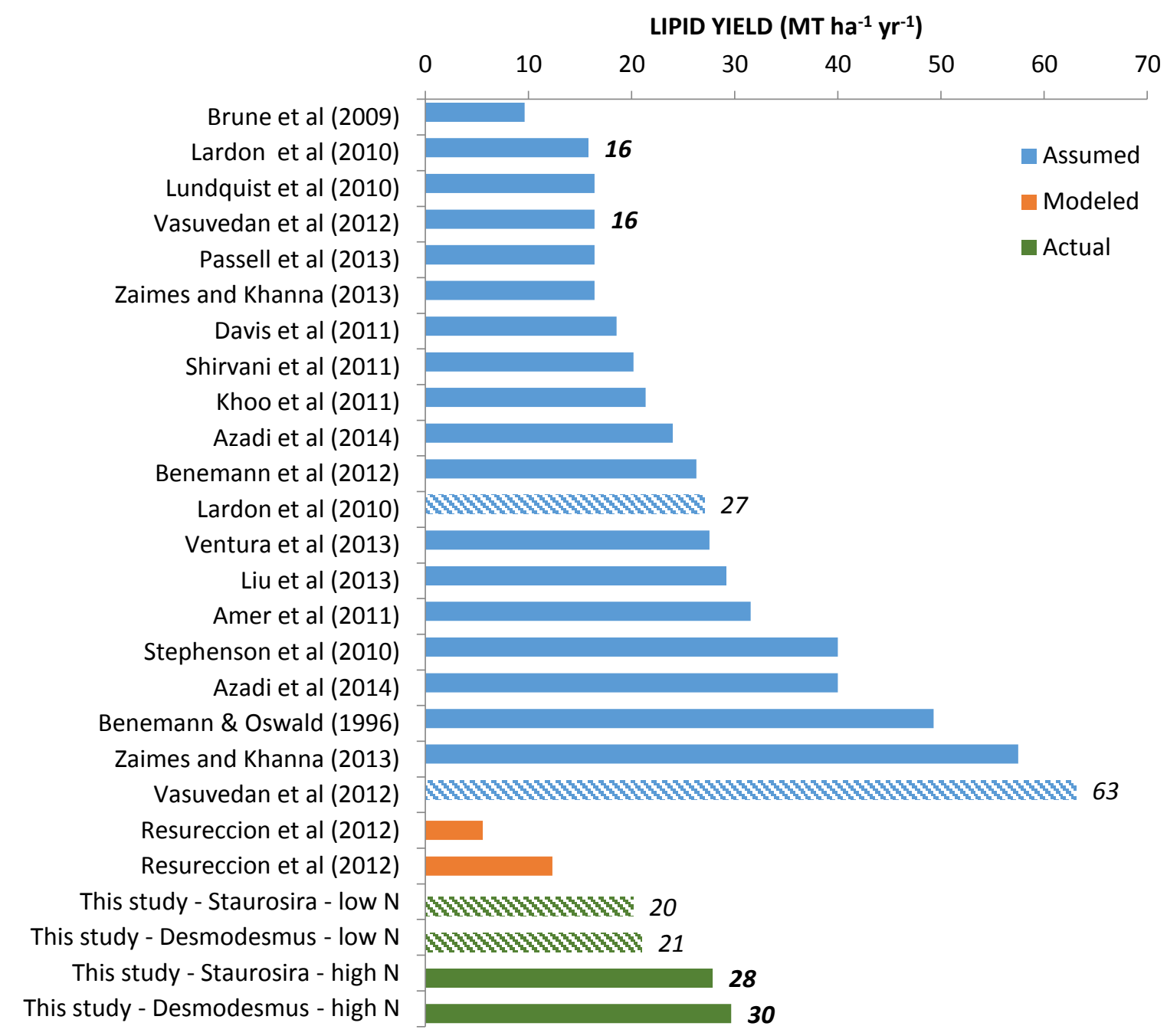

Figure 13 Reported annual yields of algal oil $\left(\mathrm{MT} \mathrm{ha}^{-1} \mathrm{yr}^{-1}\right)$ in techno-economic and/or life cycle assessment studies of three types: using (a) assumed, (b) modeled, and (c) realized values of productivity for pond systems $>10 \mathrm{~m}^{2}$, compared to values reported here for Staurosira and Desmodesmus. Low $\mathrm{N}$ treatments: hatched bars, data labels in italics. High $\mathrm{N}$ treatments: solid bars, data labels in bold italics. References: [3-13, 15, 17, 22] 